\title{
Allocative and Informational Externalities in Auctions and Related Mechanisms*
}

\author{
Philippe Jehiel and Benny Moldovanu
}

14.12 .2005

\begin{abstract}
We study the effects of allocative and informational externalities in (multiobject) auctions and related mechanisms. Such externalities naturally arise in models that embed auctions in larger economic contexts. In particular, they appear when there is downstream interaction among bidders after the auction has closed. The endogeneity of valuations is the main driving force behind many new, specific phenomena with allocative externalities: even in complete information settings, traditional auction formats need not be efficient, and they may give rise to multiple equilibria and strategic non-participation. But, in the absence of informational externalities, welfare maximization can be achieved by Vickrey-Clarke-Groves mechanisms. Welfare-maximizing BayesNash implementation is, however, impossible in multi-object settings with informational externalities, unless the allocation problem is separable across objects (e.g. there are no allocative externalities nor complementarities) or signals are one-dimensional. Moreover, implementation of any choice function via ex-post equilibrium is generically impossible with informational externalities and multidimensional types.
\end{abstract}

*Invited lecture at the World Congress of the Econometric Society, London , 2005. 


\section{Introduction}

General equilibrium analysis has identified several forms of externalities as obstacles on the road towards economic efficiency. The First Welfare Theorem fails in the presence of allocative externalities, i.e., when agents care about the physical consumption bundles of others. Akerlof's (1970) famous analysis demonstrated that the First Welfare Theorem may also fail in the presence of informational externalities, i.e., when agents care about the information held by others.

In contrast to general equilibrium analysis, auction theory is based on the premise of individual strategic behavior. This theory offers explicit models of price formation and allocative distribution that can be applied also to small markets. The belief that auctions yield competitive outcomes even if information is dispersed is behind the practical appeal of auctions, and behind their recent popularity.

Since Walrasian equilibria need not be efficient in the presence of various forms of externalities, it is of interest to understand what are the parallel consequences of external effects in auctions, and in other related mechanisms. This is the main purpose of the research summarized in the present paper.

Traditionally, the focus of auction theory has been on models that view auctions as isolated events. In practice, however, auctions are often part of larger transactions: for example, in privatization exercises such as license allocation schemes (see Jehiel and Moldovanu, 2003, and the surveys in Janssen, 2004), auctions shape the size and composition of future markets. Thus the auction typically affects the nature of the post-auction interaction among bidders. On the other hand, anticipated scenarios about the future interaction influence bidding behavior: already at the bidding stage agents need to care about who gets what, and about the information revealed to, or possessed by others, since these features will be reflected in the equilibrium of the post-auction interaction. Thus allocative and informational externalities naturally arise in models that embed auctions in larger economic contexts. 
This constitutes the main motivation for the present study.

In Section 2 we present a social choice model with a finite number of alternatives and transferable utilities that includes, as a special case, a general multi-object auction model where the alternatives are partitions of objects among agents. The model can incorporate allocative and informational externalities, as well as complementarities. We also sketch a typical application to license auctions.

In Section 3 we focus on the effects of allocative externalities. The induced endogeneity of valuations is the main driving force behind a wealth of new, specific phenomena. Traditional auction formats need not be efficient. They may create incentives for strategic non-participation and yield multiple equilibria with qualitatively different outcomes. We note that the presence of allocative externalities may also be responsible for the emptiness of the core, thereby suggesting that allocative externalities may be an important source of (coalitional) instability. We discuss the use of optimal threats in revenue maximization, and the conflicts that arise among various designer's goals, such as welfare maximization and revenue maximization. In particular, flexible auction formats need not be preferable as they may allow bidders to achieve more concentrated market structures.

Furthermore, we observe that in environments with limited commitment abilities, resale markets ensure that, in the long run, the welfare performance is unaffected by the initial allocation of property rights if agents are patient enough. But the final outcome induced by the resale markets need not be efficient, thereby suggesting that a desirable initial allocation coupled with restrictions on the resale markets may be preferable. The section ends with a brief survey of applications.

In Section 4 the emphasis is on informational externalities, and on several impossibility results in such frameworks. In order to consistently and generally model the preferences of bidders, private signals must be vectors rather than scalars. This feature distinguishes our framework from most auction models for a single object (that 
were the traditional domain of much of auction theory $)^{1}$. Analyzing incentive constraints with multidimensional signals is technically complex, but indispensable. For the general social choice model developed in Section 2 we characterize Bayes-Nash incentive compatible mechanisms under the assumption that signals are independent. A key requirement is that equilibrium utility (as a function of type) is a convex potential. Simple corollaries include general payoff and revenue equivalence theorems.

We next proceed to show that, in the presence of informational externalities, Bayes-Nash implementation of the welfare-maximizing choice function is impossible in generic settings with multidimensional signals. Thus, welfare-maximizing multi-object auctions do not exist, unless the allocation problem is separable across objects (e.g., there are neither allocative externalities nor complementarities) or signals are one-dimensional. This is in sharp contrast with the case of private values (no informational externalities) in which the celebrated Vickrey-Clarke-Groves mechanism ensures that welfare-maximizing choice rules can be implemented in dominant strategy whatever the dimensionality of the private information held by agents (and whether or not there are allocative externalities).

We next explore which social choice rules can be robustly implemented in the presence of informational externalities, where robust implementation refers to implementation via mechanisms that do not finely depend on the beliefs of the agents or designer. In contexts with informational externalities, robust implementation is associated with ex-post implementation, which is the analog of implementation in dominant strategy in the private values setup. It turns out that no social choice rule that makes use of the private information can be ex post implemented, as soon

\footnotetext{
${ }^{1}$ For one-object auction models that allow for several informational dimensions (e.g., on a private value component and common value component), see, among others, Maskin (1992), Pesendorfer and Swinkels (1998), Compte and Jehiel (2002a), and Jackson (2003).
} 
as two agents have at least two dimensions of private information. We contrast this impossibility result with the characterization of dominant-strategy implementable social choice rules for private values setups obtained by Roberts (1979). We also identify non-generic settings where ex-post implementation and ex-post welfaremaximization are possible. Section 5 concludes.

We wish to emphasize here that the present paper is not meant to be a survey of auction theory and mechanism design: there is a wealth of interesting and relevant issues that will not be addressed here. Interested readers can consult, for example, Klemperer (1999) or Milgrom (2004).

\section{A General Multi-Object Auction Model}

We start with a general social choice model with $N+1$ agents, indexed by $i=$ $0,1,2, . . N$ and $K$ social alternatives, indexed by $k=1,2, . . K$. Each agent gets a private signal about the state of the world $\theta^{i} \in \Theta^{i} \subseteq \Re^{m}$. We denote $\theta=$ $\left(\theta^{0}, \theta^{1}, \ldots \theta^{N}\right), \Theta=\times_{i=0}^{N} \Theta^{i}, \theta^{-i}=\left(\theta^{0}, \ldots, \theta^{i-1}, \theta^{i+1}, \ldots, \theta^{N}\right)$ and so on...

Agents have quasi-linear utility functions that depend on the chosen alternative, on private signals, and on monetary payments: if alternative $k$ is chosen, and if agent $i$ obtains a monetary transfer $t^{i}$, then her utility ${ }^{2}$ is given by $u^{i}\left(k, \theta, t^{i}\right)=$ $v_{k}^{i}\left(\theta^{0}, \theta^{1}, \ldots \theta^{N}\right)+t^{i}$ where $v_{k}^{i}$ may, a priori, be any function of $\left(\theta^{0}, \theta^{1}, \ldots \theta^{N}\right)$.

The special case of auctions is included as follows: A set of $M$ objects (possibly heterogenous) is allocated among a seller (who will be called agent zero) and $N$ potential buyers. Here a social alternative is a partition of the goods among the agents: $P=\left(P_{0}, P_{1}, . . P_{N}\right)$, where $P_{i}$ represents the bundle allocated to agent $i$. Let

\footnotetext{
${ }^{2}$ More generally, agent $i^{\prime}$ s utility may depend also on monetary transfers made to other players. These are situations with "financial externalities". We do not include them in our present analysis. The reader interested in the effect of such externalities on auctions should consult Dasgupta and Tsui (2004), Ettinger (2002) and Goeree et al. (2004).
} 
$\mathcal{P}$ denote the set of all partitions.

For each partition $P$, agent $i$ obtains a signal $\theta_{P}^{i}$ that influences values for that partition. Thus $\theta^{i}=\left(\theta_{P}^{i}\right)_{P \in \mathcal{P}}$, and we write $v_{P}^{i}(\theta)=v_{P}^{i}\left(\theta_{P}^{0}, . ., \theta_{P}^{N}\right)$. This specification includes a large variety of auction / mechanism design models studied in the literature. Here are a few prominent examples:

1) For any partitions $P$ and $P^{\prime}$ such that $P_{i}=P_{i}^{\prime}$ assume that $\theta_{P}^{i}=\theta_{P^{\prime}}^{i} \equiv$ $\theta_{P_{i}}^{i}$, and $v_{P}^{i}(\theta)=v_{P^{\prime}}^{i}(\theta) \equiv v_{P_{i}}^{i}\left(\theta_{P_{i}}^{i}\right)$. This is a "pure private values" model where agent $i$ only cares about the bundle allocated to her in each partition, and about a signal pertaining to that bundle. There are neither allocative nor informational externalities.

2) For any $\theta$ and $\theta^{\prime}$ such that $\theta_{P}^{i}=\theta_{P}^{\prime i}$, assume that $v_{P}^{i}(\theta)=v_{P}^{i}\left(\theta^{\prime}\right) \equiv v_{P}^{i}\left(\theta_{P}^{i}\right)$. This is a model where agent $i$ only cares about his own signal about the partition, (i.e., there are no informational externalities), but $i$ may care about the entire partition of objects (i.e., there are allocative externalities)

3) For any partitions $P$ and $P^{\prime}$ such that $P_{i}=P_{i}^{\prime}$ assume that $v_{P}^{i}(\theta)=v_{P^{\prime}}^{i}(\theta)$. It follows that $\theta^{j}$ can be re-parameterized as $\theta^{j}=\left(\theta_{X}^{j}\right)_{X \in 2^{M}}$ where $X$ is a subset of the $M$ objects, and $v_{P}^{i}(\theta)$ can be re-written as $v_{P_{i}}^{i}\left(\theta_{P_{i}}^{0}, \ldots, \theta_{P_{i}}^{N}\right)$. This is a model where agent $i$ only cares about the bundle allocated to him in each partition (i.e., there are no allocative externalities), but $i$ does care about the information about that bundle available to other agents (i.e., there are informational externalities).

4) $v_{P}^{i}(\theta)$ depends in a general way on the entire partition $P$ and on the entire profile of signals $\theta$. This is the most general model that admits both allocative and informational externalities.

5) Assume that there are no allocative externalities. If $v_{P_{i} \cup P_{i}^{\prime}}^{i}(\cdot)>(<) v_{P_{i}}^{i}(\cdot)+$ $v_{P_{i}^{\prime}}^{i}(\cdot)$ for some bundles of object $P_{i}, P_{i}^{\prime}$, then this is a model that exhibits complementarities (substitutabilities).

\section{A Typical Application}


In industrial organization contexts, allocative externalities often arise because bidders care about the ensuing market structure that is affected by the auction's outcome. Informational externalities arise because private information on the cost structure typically affects the competitors' profits. Finally, information is naturally multi-dimensional because there are various aspects to the cost structure and different objects for sale.

As an illustration, consider the recent European process of allocating UMTS licenses to telecom firms (for further details, see Klemperer, 2002 and Jehiel and Moldovanu, 2003). The allocation proceeded via a sequence of national auctions and beauty contests. We focus below only on the basic features that parallel those in the model sketched above:

1) The auctioned objects were licenses to operate a third-generation mobile telephony network in a certain country. The licenses differed in a multitude of dimensions such as the size and distribution of the population, spectrum capacity, duration, required investment size and deployment speed, etc...Private information was multidimensional since many types of licenses were sold, and since the bidding firms had heterogenous assessments about technical network requirements, present and future regulatory frameworks, future demand characteristics, future operation costs, etc...

2) The value of a bundle of licenses for a given firm is given by the expected revenue in the future market from holding that bundle, minus the required infrastructure and operation costs. The expected profit crucially depends on the number of licenses (or competitors) within one country, on their identity (e.g., small local firms or large supranational ones), on the license holdings of competitors in other countries (that determine what integrated services they can offer), and so on... Thus, a major feature was the presence of allocative externalities 
3) In any reasonable oligopoly scenario, competitors' cost parameters ${ }^{3}$ affect one own's profit. Since competitors were likely to have some information about their operation method, future technological development and future demand, the auctions also involved informational externalities.

\section{$3 \quad$ Allocative Externalities}

In this section we review design issues that are related to the presence of allocative externalities. In order to abstract from other effects, we first assume that there is complete information, and we come back later to the additional phenomena due to asymmetric information.

We illustrate a number of insights through the following situation appearing in Industrial Organization models: There are $N$ potentially active firms in the market. An innovation protected by a patent is auctioned among the firms. The acquiring firm is able to produce at a lower cost, but the magnitude of the cost reduction may depend on the identity of the acquiring firm. Let $v_{i}^{i}$ denote the change in profit of firm $i$ if $i$ acquires the innovation; $v_{i}^{i}$ is referred to as $i$ 's valuation. Let $v_{i}^{j}$ denote the change of profit of firm $j$ when firm $i$ acquires the innovation. This change of profit is caused by the modified oligopolistic competition after the innovation is introduced (which is typically less favorable for $j$ ). We refer to $v_{i}^{j}$ as the externality exerted by $i$ on $j$. This specification fits into the general model presented above by noting that, in the case of one single object, the partition $P$ can be simply described by the firm $i$ who acquires the innovation.

\footnotetext{
${ }^{3}$ This is just an example; information about demand parameters is another.
} 


\subsection{Endogenous Valuations}

Assume that the innovation is auctioned using a second-price sealed-bid auction ${ }^{4}$. That is, each firm $i$ submits a bid $b_{i}$, and the firm with highest bid wins the auction and pays the second highest bid. Ties are resolved as usual.

In the traditional setup without externalities, it is a (weakly) dominant strategy for firms to bid their values for the auctioned object (see Vickrey, 1961). Here, the mere notion of value is not well defined. Indeed, how much $i$ is willing to pay in order to win very much depends on her expectation about who is going to win if she does not. For example, if $i$ expects $j$ to win her net value of winning (compared to the loss scenario) is $v_{i}^{i}-v_{j}^{i}$. Similarly, if $i$ expects $k$ to win her value is $v_{i}^{i}-v_{k}^{i}$. These two values need not coincide, and thus it is impossible to say how much $i$ values the innovation, independently of her expectations over alternative market scenarios. Of course, expectations must be consistent with equilibrium play. The observation that valuations depend here on expectations translates into the possibility of multiple equilibria with quite different outcomes:

Example 1 (Jehiel and Moldovanu, 1996) Let $N=3$, and let $v_{i}^{i}=v$ for all $i$. Let the externality terms be: $v_{1}^{2}=v_{2}^{1}=-\alpha, v_{1}^{3}=v_{2}^{3}=-\gamma$, and $v_{3}^{1}=v_{3}^{2}=-\beta$ where $\alpha>\gamma>\beta>0$.

It is readily verified that, in one equilibrium, firms 1 and 2 compete with each other (since they are very afraid of each other). The resulting outcome is that either firm 1 or 2 wins the auction and pays $v+\alpha$. In another equilibrium, 1 and 3 are in competition. The resulting outcome is that 3 wins the auction (because 3 is more afraid of 1 than 1 is afraid of 3, e.g. $\gamma>\beta$ ) and pays $v+\beta$ - a much lower price than in the previous equilibrium. Firm 2 is not willing to outbid 3 because 2 is not that afraid of 3 .

\footnotetext{
${ }^{4}$ The same insights apply to all other standard formats.
} 


\subsection{Strategic Non-Participation}

In auctions without externalities, not participating in the auction is equivalent to participating and making an irrelevant $\mathrm{bid}^{5}$. In the presence of externalities, this is no longer the case. By staying out, a bidder may induce an outcome that turns out to be more favorable to her than the outcome that would have arisen if she had participated (see Jehiel and Moldovanu, 1996). We illustrate it through the following example:

Example 2 (Hoppe, Jehiel and Moldovanu, 2005) Let $N=3$. Firms 1, 2 are incumbents, while firm 3 is a potential entrant. The incumbents do not value the object (innovation, license, etc...) per se: $v_{1}^{1}=v_{2}^{2}=0$. Moreover, $v_{1}^{2}=v_{2}^{1}=0$. The entrant has value $v_{3}^{3}=v$, and it creates an externality $v_{3}^{1}=v_{3}^{2}=-\alpha$ on incumbents. We assume that $v<\alpha$.

If all firms participate, there are, essentially, three continuation equilibria: two in pure, and one in mixed strategies. In a pure strategy equilibrium, one of the incumbents, say firm 1 , wins and pays $v$. In this equilibrium firm 2 bids zero since there is no point winning: that outcome is equivalent to the outcome when she lets 1 win. In the mixed strategy equilibrium, firms 1 and 2 mix between a bid of zero (say), and a bid slightly above $v$, and the entrant sometimes wins. The strategic interaction between incumbents resembles a war of attrition: each incumbent is willing to deter entry but prefers that the other one pays the price of entry deterrence. Assume then that one of the above bidding equilibria is played. At least one incumbent, say 1 , wins at price $v$ with positive probability. But, 1 would be strictly better off by not participating in the auction. In that case, the auction is among bidders 2 and 3 , and 2 wins because $\alpha>v$. Clearly, firm 1 benefits

\footnotetext{
${ }^{5}$ Participation costs are assumed to be nul.
} 
from such a deviation. Thus, in any equilibrium, at least one of the firms will choose not to participate with positive probability ${ }^{6}$.

In Hoppe, Jehiel and Moldovanu (2005), we build on Example 2 to show that increasing the number of objects may change the nature of the interaction between the incumbents. When two objects are auctioned, the two incumbents have an easy way to collude within the auction: each buys one object at price $v$, thereby deterring entry. If allowing two entries is also an equilibrium, the two-object auction resembles now a coordination game between the two incumbents, rather than a war of attrition (as in the one-object auction). This is somewhat reminiscent of the finding that, in multi-object auctions, collusion may mean sharing the items for sale (see Wilson 1979). But, the channel through which this occurs here is specific to the presence of allocative externalities.

\subsection{Participation Decisions and Optimal Mechanisms}

We considered above standard auction formats. We wish now to analyze how the auction designer can exploit the bidders' participation decisions in order to increase her revenue. The key observation is that, by augmenting the auction design by appropriate threats, the designer is able to extract payments also from bidders who do not win. This subsection summarizes insights from Jehiel, Moldovanu and Stacchetti (1996) (see also Kamien, Oren and Tauman 1992 for an early analysis of a setting where non-acquirers make payments to the auctioneer).

Assume that all externalities are negative, i.e., $v_{i}^{j} \leq 0$ for all $i, j \neq i$. If firm $i$ stays out, the worst scenario for firm $i$ would be that the winner is firm $j(i)$ where $j(i) \in \arg \min _{j} v_{j}^{i}$. We let $\underline{v}^{i}=\min _{j \neq i} v_{j}^{i}$, and augment the mechanism by

\footnotetext{
${ }^{6}$ The argument assumes that the set of participants is public information. One way to avoid strategic non-participation is to keep the set of bidders secret. But, such policies may have other drawbacks (see Compte and Jehiel, 2002b and DasVarma, 2002).
} 
the specification that if agent $i$ does not participate, the winner is firm $j(i)$. In line with the mechanism design literature we assume first that the designer has the commitment power to implement such threats.

If firm $i$ refuses to participate, it will get a minimal payoff. In equilibrium ${ }^{7}$, all firms participate, and the outcome is chosen so as to maximize welfare. This is so because the designer can internalize social welfare by asking every firm $i$ to pay the difference between $i$ 's payoff in the welfare maximizing outcome and $\underline{v}^{i}$.

Proposition 3 The outcome of the revenue maximizing mechanism also maximizes welfare for the agents. The extracted revenue is $R=-\sum_{i} \underline{v}^{i}+\max \left\{0, \max _{i} \sum_{j} v_{i}^{j}\right\}$

The above argument can be viewed as an expression of the celebrated Coase theorem $^{8}$. Observe that, in the presence of allocative externalities, as soon as there are at least three bidders, welfare is usually not maximized by standard auctions.

To illustrate Proposition 3, consider example 2 again. Given that $v<\alpha$, the outcome that maximizes welfare (among agents) is that the object is sold to either incumbent (or, equivalently, that the seller keeps the object). The threat to either incumbent is that, if either of them refuses to participate, the object is sold to the entrant. The entrant is not threatened. Each incumbent is willing to pay $\alpha$ to avoid entry, and the revenue to the designer is $2 \alpha^{9}$.

More generally, if the designer also cares about consumers' surplus and not only about revenue, then total welfare will be maximized in equilibrium, and the payoff

\footnotetext{
${ }^{7}$ There could, a priori, be equilibria where several firms decide not to participate. But, by suitably defining what the mechanism does when several firms do not participate, one can guarantee that participation is a weakly dominant strategy. (see Jehiel et al., 1996).

${ }^{8}$ This holds despite the fact that the participation constraints are endogenous, unlike those in Coase's original analysis. The point is that reservation values can be set independently of the chosen outcome.

${ }^{9}$ If we restrict attention to mechanisms where only the winner can make payments, the revenue falls down to $\alpha$.
} 
of the designer will be given by $W=-\sum_{i} \underline{v}^{i}+\max \left\{0, \max _{i}\left(\sum_{j} v_{i}^{j}+C S_{i}\right)\right\}$ where $C S_{i}$ is the change in consumers' surplus resulting from a sale to firm $i$.

\subsection{Credibility and Resale}

In the above application, the designer can commit to personalized and fine-tuned threats. What happens if commitment power is limited? In Jehiel and Moldovanu (1999) we consider ${ }^{10}$ a model where firms can sell and further resell the object before a (sufficiently far away) deadline $T$, at which time the current owner of the good must use it. We assume that agents are unable to commit to actions at future stages (in particular, they are unable to commit not to resell, or to sell to a specific agent if some pre-specified event occurs). At each stage, the current owner makes an offer to a set of agents. The offer may include a sale in exchange for payments. If an approached agent refuses the deal, one period of time elapses, and the owner makes a new offer. The main finding of Jehiel and Moldovanu (1999) is:

Proposition 4 : The identity of the initial owner does not affect the identity of the agent who consumes at date $T$. The consumer at date $T$ need not maximize total welfare unless all agents have veto power over all transactions.

The following example illustrates the result:

Example 5 Let $N=4$, and let $T \geq 2$. The values are: $v_{1}^{1}=6.5, v_{2}^{2}=10.1, v_{3}^{3}=9$, $v_{4}^{4}=7 ; v_{1}^{2}=v_{1}^{3}=v_{1}^{4}=0 ; v_{2}^{1}=v_{2}^{3}=-1, v_{2}^{4}=-2 ; v_{3}^{1}=-2, v_{3}^{2}=0, v_{3}^{4}=-1$; $v_{4}^{1}=v_{4}^{2}=0, v_{4}^{3}=-1$.

The welfare maximizing firm is 1 . But, no matter who the initial owner is, the object will be consumed by firm 2 at stage $T$. At stage $T-1$, firm 1 sells to 2 without

\footnotetext{
${ }^{10}$ See also Brocas (2003) for a study of an auction with negative externalities where the seller has no credible threats.
} 


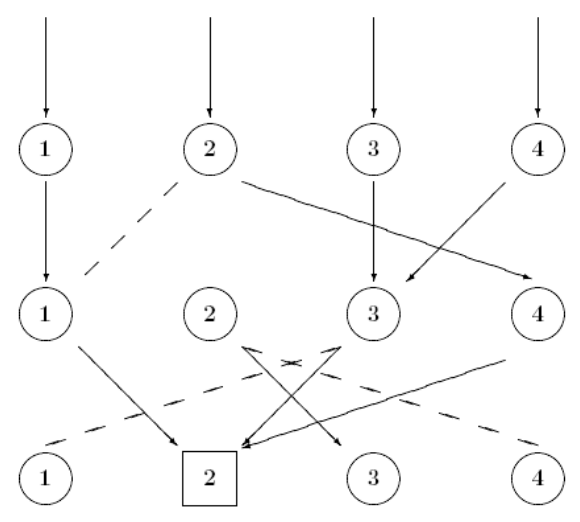

extracting any payment from 3 and 4 because these prefer that 1 is the final owner rather than 2. Firm 2 sells to 3 while extracting $v_{3}^{4}-v_{2}^{4}=1$ from 4 . Firm 3 sells to 2 while extracting $v_{2}^{1}-v_{3}^{1}=1$ from 1 .Firm 4 sells to 2 without extra payments from 1 and 3 . At stage $T-2$, firms 1 and 3 do not sell. Firm 2 sells to 4 while extracting $v_{2}^{1}-v_{3}^{1}=1$ from firm 1 . Firm 4 sells to 3 without extra payment from firms 1 and 2. At stage $T-3$ and any earlier stages, no matter who is the current owner, the innovation ends up in the hands of firm 2 at stage $T$.

A main feature of the above equilibrium is that, at some stages, firms that oppose the deal are simply excluded from the agreement. Veto power (i.e., the consent of all agents is needed for a change of ownership) restores efficiency.

If, resale cannot be forbidden, the above result suggests that it is welfare irrelevant how the initial property rights are assigned: eventually the same final physical outcome results. But, it is erroneous to conclude that mechanism design is irrelevant. Indeed, since the final outcome need not be efficient, it may be a good idea to try to allocate the object efficiently in the first place, and then control the resale market to some extent ${ }^{11}$.

\footnotetext{
${ }^{11}$ An extreme option is to forbid resales, as was done in the case of spectrum license auctions.
} 
There are several limitations to the above model: 1) The result relies on the existence of a deadline ${ }^{12} ; 2$ ) There is only one object for sale; 3) Only the current owner is able to make proposals. Gomes and Jehiel (2005) were able to generalize the main result without these assumptions. They also show that efficiency must occur in the long run if the efficient allocation of goods is such that no group of agents can force a move to another allocation that hurts $i$ without her consent.

\subsection{Core and Externalities}

We make now a brief detour to remind the reader that, from the viewpoint of coalitional deviations, the presence of allocative externalities is a source of instability. The following result is a corollary of Proposition 6 in Jehiel and Moldovanu (1996).

Proposition 6 Suppose that welfare is maximized by letting firm $i^{*}$ buy the object. If there exists a subset $T$ of buyers, $i^{*} \notin T$, and a buyer $i \in T$ such that $\sum_{j \in T \cup\left\{i^{*}\right\}} v_{i^{*}}^{j}<$ $\sum_{j \in T \cup\left\{i^{*}\right\}} v_{i}^{j}$ then the core of the associated market with externalities is empty ${ }^{14}$.

The intuition for the above Proposition is as follows: stability against coalitional deviations requires welfare maximization, so that in any core outcome the object is sold to $i^{*}$. Buyers $j \neq i^{*}$ can always refuse to make any payment, and buyers $j \neq$

\footnotetext{
${ }^{12}$ Chien (2004) analyzes the same model with an infinite horizon and focuses on the resulting differences

${ }^{13}$ When condition (??) holds, the welfare maximizing state $i^{*}$ is not negative externality-free (see Gomes and Jehiel 2005) since the coalition of the seller and buyers in $T$ can allocate the object to $i$, hurting agents outside $T \cup\left\{i^{*}\right\}$. The spoliation is the key reason for the inexistence of a stable outcome.

${ }^{14}$ With externalities, the core notion depends on assumptions about reactions to coalitional deviations by agents in the complement. Our result holds for the most permissive definition, the $\alpha$-core, where the complement is assumed to choose the worst course of action from the point of view of the deviators. Any core is empty if the $\alpha$-core is.
} 
$i$ are thus assured to get at least $\sum_{j \neq i^{*}} v_{i^{*}}^{j}$ collectively. Buyer $j$ cannot get strictly more than $v_{i^{*}}^{j}$ as otherwise the coalition of the seller and firm $i^{*}$ could do better by just ignoring $j$. Thus, $j$ must get exactly $v_{i^{*}}^{j}$. Thus, if above condition holds, the coalition of the seller and buyers in $T \cup\left\{i^{*}\right\}$ can improve on the candidate core allocation by re-allocating the object to $i$ rather than $i^{*}$. It follows that the core must be empty.

\subsection{The Conflict between Welfare and Revenue}

In this subsection, we briefly consider an auction where the number of auctioned objects is endogenously determined by the bidders' behavior, and where externalities are created by the effects on downstream payoffs ${ }^{15}$.

Consider spectrum auction. Conventional wisdom suggests that disaggregating spectrum, say, into small capacity blocks, and letting the bidders aggregate the blocks to form licenses of whatever capacity they need is a good idea. After all, the designer is usually not knowledgeable about how much the firms value the licenses, or about how valuable extra capacity is. But, this argument ignores the possibility that the auction's flexibility may be used by firms to induce concentrated market structures.

Example 7 There are four identical blocks for sale, and let $N=5$. A bidder needs at least one block (small license), and bidders may buy up to two blocks (large license). Each bidder $i$ submits a schedule $b_{i}=\left(b_{i}(1), b_{i}(2)\right)$ where $b_{i}(m)$ is the bid for $m$ blocks, $m=1,2$. Blocks are allocated and payments are made according to a uniform price auction. For any partition $P$ of the four blocks in which firm i receives $m$ blocks, and a total of $n$ firms get at least one block, define $v_{P}^{i}=\pi(m, n)$.

\footnotetext{
${ }^{15}$ This is inspired by the German UMTS license auction that took place in 2001. The treatment follows Jehiel and Moldovanu (2003).
} 
If $\pi(2,2)-\pi(1,3)>\pi(1,3)$, the auction outcome is a duopoly because the extra profit gained by switching from a small license in a triopoly to a large license in a duopoly is larger than the profit with a small license in triopoly. That is, two firms buy two blocks each, the equilibrium price for a block is $\pi(1,3)$, and a winner pays $2 \pi(1,3)$. In contrast, a less flexible format could, for example, mandate that three licenses (two small, one big) are sold. The assessment of the two formats depends, basically, on the partial derivatives of $\pi$. If the derivative with respect to capacity is larger (presumably it is positive), the flexible format is likely to be preferable. If, however, the derivative with respect to the size of the market (presumably negative) is larger, then the less flexible format is likely to be preferable because of the increased consumer surplus in a less concentrated market.

Sometimes it is also argued that welfare maximization for bidders and revenue go hand in hand in auctions ${ }^{16}$. But, again this view ignores that "value", and hence "revenue" may be driven by the desire to squeeze consumers' surplus. Since the value of a monopoly position is larger than the combined values of oligopolists, it is intuitive that an auction for monopoly (which is a form of bundling ) will yield more revenue than an auction that creates several winners that compete against each other (at an extreme such an auction yields no revenue at all if firms expect a "Bertrand" type of interaction). But welfare, including consumer surplus, will be small under monopoly. Thus, revenue and efficiency may be quite unrelated to each other if there are allocative externalities (see also Janssen and Moldovanu, 2004).

\footnotetext{
${ }^{16}$ There are many caveats to this claim even without allocative externalities. For example, revenue maximization requires the use of reserve prices, or handicaps in asymmetric contexts, or quantity discounts in multi-object auctions.
} 


\subsection{Private information}

Private information on allocative externality terms can yield private value models without informational externalities if $i$ knows the externality terms $v_{j}^{i}$ caused to her, or it can yield interdependent value models if $i$ has private information on the externality terms $v_{i}^{j}$ she causes to others (of course, mixtures are also possible).

Jehiel and Moldovanu (2000) analyze a sealed-bid second-price auctions with entry fees and reserve prices in a model where bidders have one dimensional private information that influences both their valuations, and the externality terms. Specifically, in a two bidder model, $\theta^{i}=v_{i}^{i}$ is private information, and $v_{j}^{i}$ is a function of both $\theta^{i}$ and $\theta^{j}$, i.e. $v_{j}^{i}\left(\theta^{i}, \theta^{j}\right)$. This model captures situations where each firm has private information about the reduction on marginal cost induced by an innovation, and where the cost structure is public information before the market interaction.

This model displays both private and interdependent value components: when $i$ compares the alternative where he wins to the one where the seller keeps the object, his net value is $\theta^{i}$. When $i$ compares the alternative where he wins with the one where the other bidder wins, his net value is $\theta^{i}-v_{j}^{i}\left(\theta^{i}, \theta^{j}\right)$, which depends both on $i$ and $j$ 's private information. Only the second comparison is relevant if there is no reserve price, and then the analysis is analogous to the one in Milgrom and Weber' (1982) framework: in a symmetric two-bidder setting, i.e., $v_{j}^{i}(x, y) \equiv v_{i}^{j}(x, y)=e(x, y)$, where the function $x \rightarrow x-e(x, x)$ is increasing, type $\theta^{i} \operatorname{bids}^{17} b\left(\theta^{i}\right)=\theta^{i}-e\left(\theta^{i}, \theta^{i}\right)$.

The auction with a reserve price $R$ is more interesting. For the sake of illustration, assume that the externality function is given by a constant $-e$, where $e \geq 0$, and consider $R$ inside the support of valuations ${ }^{18}$. The equilibrium is such that bidders with valuation below $R$ bid below $R$, (say zero), and bidders with valuations above

\footnotetext{
${ }^{17}$ With more than two bidders and with asymmetries, the features mentioned in the above subsections (multiplicity of equilibria, strategic non-participation, etc...) appear also here.

${ }^{18} \mathrm{We}$ also assume that the valuations are identically and independently distributed.
} 
$R$ bid Thus, there is no relevant bid between $R$ and $R+e^{19}$. The reason for this discontinuity is as follows: when the marginal type $v_{i}^{i}=R$ considers whether to make a relevant bid or not, the benchmark is that the seller keeps the object. As soon as a bidder makes a relevant bid, the effect of marginally decreasing the bid is now that the other bidder sometimes wins. Thus, in the relevant bid area, the bid function must be $\theta^{i}+e$.

Another interesting observation is that the seller's optimal reserve price may be below the seller's valuation, a situation that never occurs without externalities ${ }^{20}$. The reason is that, selling more often frightens bidders when there are negative externalities, and therefore they bid higher in order to win.

In the case of positive externalities, the equilibrium bidding function still has two distinct parts. But consistently combining the two parts requires now that a positive measure of valuations $\theta^{i}$ bids $R^{21}$. Moreover, with positive externalities, entry fees and reserve prices need not lead to equivalent revenues.

Moldovanu and Sela (2003) study a patent auction where the post-auction interaction is à la Bertrand. There, the analog of the function $\theta^{i}-v_{j}^{i}\left(\theta^{i}, \theta^{j}\right)$ is decreasing and pooling occurs even with negative externalities. Goeree (2000), Das Varma (2003) and Molnar and Virag (2004) study a variant of the above model where the cost structure is not made public after the auction. In this case, the winning bid has the extra feature of conveying some information about the cost structure of the winning bidder, and there is an extra signaling motive appearing in the bidding strategy.

We now briefly consider revenue-maximizing auctions. There are two difficulties linked to the presence of allocative externalities: 1) Information is typically multidi-

\footnotetext{
${ }^{19} \mathrm{~A}$ similar discontinuity may arise in the affiliated model of Milgrom and Weber (1982).

${ }^{20}$ The optimal reserve price also depends on the number of bidders.

${ }^{21}$ Pooling also appears in the resale auctions studied by Haile (2000). The possibility of resale translates into a "reduced form" positive externality.
} 
mensional; 2) Participation constraints are typically determined by the mechanism itself and are type-dependent.

Jehiel, Moldovanu and Stacchetti (1999) consider a symmetric, private values setup with multidimensional private information and negative externalities: bidder $i$ knows her valuation $v_{i}^{i}$ and the externalities $v_{j}^{i}$ caused to her. For example, the unique symmetric equilibrium of a second-price auction among $N$ bidders is given by $b\left(v_{i}^{i}, v_{-i}^{i}\right)=v_{i}^{i}-\frac{1}{N-1} \sum v_{j}^{i}$. Thus, the equilibrium bids are set at valuation minus average externality.

As in the complete information case (see subsection 3.3), the optimal auction will include some threat in case a bidder does not participate. But, in this private value model, there is no way to fine-tune the threat for $i$ by using information revealed by others. It turns out that it is enough to care about the participation constraint of the type whose valuation is smallest and whose externalities are closest to zero. The threat (taking the form of a fixed allocation rule in case $i$ does not participate) can be designed so that the participation constraints of all other types of bidder $i$ are automatically satisfied as soon as $i$ 's incentive constraints are satisfied. Thus, even though participation constraints are a priori type-dependent, the fact that they are endogenously determined by the mechanism (through the choice of threats) allows us to avoid some of the complications inherent to exogenous type-dependent participation constraints ${ }^{22}$.

Jehiel, Moldovanu and Stacchetti (1999) show that a second-price auction with an appropriately defined entry fee is the revenue-maximizing mechanism in a class of mechanisms where the object is always sold, and where agents are constrained to make one-dimensional bids. They also characterize the equilibrium of the second price auction with reserve prices, and show that it is never optimal to set a small reserve price. Thus, either there should be no reserve price or the reserve price

\footnotetext{
${ }^{22}$ See Jullien (2000) for an analysis of such constraints in one-dimensional principal-agent setting.
} 
should be such that the object is not sold with a significant probability. This result cannot arise in a one-dimensional setting with a smooth, strictly positive density function, and it should also be contrasted with the finding in multidimensional monopoly problems where there is no competition among consumers. There, it is always optimal to exclude some set of consumers no matter what the support of consumers' valuations is (see Armstrong, 1996). By contrast, in the auction setup, it may be revenue-enhancing for the seller to always sell the good.

Jehiel, Moldovanu and Stacchetti (1996) construct the revenue maximizing auction in a setting where bidder $i$ knows her valuation $v_{i}^{i}$ and the negative externality $v_{i}^{j} \leq 0$ she exerts on other bidders $j$. This is a model with interdependent values (or informational externalities). If $i$ does not participate, the auctioneer optimally decides to sell the good to the agent $j(i)=\arg \min _{j} \widetilde{v}_{j}^{i}$ where $\widetilde{v}_{j}^{i}$ is agent $j$ 's report in a direct mechanism.

Figueroa and Skreta (2004) generalize the analysis of optimal mechanisms to multi-object settings with externalities, but assume that agents have one-dimensional signals $^{23}$.

Das Varma (2002) builds on the model of Jehiel, Moldovanu and Stacchetti (1999) and he observes that the ascending English auction may sometimes generate more revenue than sealed-bid auctions. This happens because bidders have incentives to stay longer in the auction in cases where their worst enemy also stays in the auction. The insight is particularly interesting in light of the revenue equivalence theorem in auctions (see subsection 4.1 below): even in a symmetric, independent, private values context with risk neutral bidders, the ascending and the sealed-bid auctions need not be revenue-equivalent if there are allocative externalities.

Caillaud and Jehiel (1998) examine the possibility of collusion in the presence of negative externalities among agents when private information bears on valuations.

\footnotetext{
${ }^{23}$ See also Caillaud and Jehiel (1998) and Brocas (2003).
} 
They show that information sharing among the ring members need not be efficient even if side-payments are allowed, which is in sharp contrast with the finding in externality-free auction setups (see, for example, Graham and Marshall, 1986).

\subsection{Applications}

Auction models with allocative externalities offer an unified framework for all situations where competing firms or agents buy important inputs that affect the nature of downstream interaction. Some effects of externalities on bidding behavior have been previously identified in the literature on the "persistence of monopoly" (see, for example, the classical paper by Gilbert and Newbery, 1982 , and also Krishna, 1993 and Rodriguez, 2002) and in the literature on patent licensing (see the classical contributions of Katz and Shapiro 1986, and Kamien and Tauman, 1986). Similar effects appear in the auctions of capacity studied by McAfee (1998). Roughly speaking, the general framework presented here extends "the persistence of monopoly" approach beyond monopoly/duopoly market structures, and it extends the literature on patent licensing by allowing for asymmetries between agents, and by considering allocation mechanisms that go beyond standard auctions.

Inderst and Wey (2004) analyze large, auction-like deals (such as privatizations, mergers and takeovers) that change the nature of an industry by affecting the number and the identity of the operating firms. It is an immediate consequence of the theory of auctions with negative externalities that a takeover premium must be observed in horizontal mergers where each firm is negatively affected if the target is acquired by another competitor.

Perez-Castrillo and Wettstein (2002), and Waehrer (2003) study the properties of bidding games and other mechanisms for allocating public goods or bads, such as siting of hazardous facilities.

Maeda (2003) and Burguet and Sempere (2005) analyze trading models for the 
emission of noxious gases. Using some insights developed for resale markets with externalities (see Jehiel and Moldovanu, 1999), Burguet et Sempere emphasize both the inadequacy of bilateral trading mechanisms for internalizing all existing externalities, and the need for multilateral schemes. A related point is made by Bagwell, Mavroidis and Staiger (2004) who propose an innovative auction of retaliation rights for dispute settlements within the World Trade Organization.

\section{Informational Externalities}

In this Section we focus on the role of informational externalities. The theoretical interest in such settings is not new. The classic contributions of Wilson (1969) and Milgrom and Weber (1981), and the large literature following them analyzed oneobject auctions with symmetric bidders. In contrast, the focus of the more recent literature is on multi-object auctions, and on the effects of asymmetries (see Maskin, 1992) on welfare-maximization.

The section will be divided in several parts. In Subsection 4.1 we develop general insights about incentive compatibility and payoff equivalence with multidimensional signals. In Subsection 4.2 we inquire whether the celebrated Vickrey-Clarke-Groves analysis can be extended to settings with informational externalities. In Subsection 4.3 we ask which social choice functions (not necessarily welfare-maximizing) can be implemented independently of the distributions of signals (i.e., in an ex-post equilibrium).

\subsection{Incentive Compatibility and Payoff Equivalence}

Recall the social choice framework described in Section 2. Agents have quasi-linear utility functions that depend on the chosen alternative $k$, on private signals $\theta=$ $\left(\theta^{0}, \theta^{1}, \ldots \theta^{N}\right)$, and on a monetary payment $t^{i}: u^{i}\left(k, \theta, t^{i}\right)=v_{k}^{i}(\theta)+t^{i}$ 
The revelation principle asserts that, for any Bayes-Nash equilibrium of any given mechanism, one can construct an equivalent equilibrium of a direct revelation mechanism where all agents truthfully report their private information. Thus, for the characterization results, we focus below on truth-telling equilibria in direct revelation mechanisms.

Denote by $v^{i}(\theta)$ the vector $\left(v_{k}^{i}(\theta)\right)_{k \in K}$, and let $\Delta^{|K|-1}$ denote the simplex of probability distributions over the finite set of alternatives. A direct revelation mechanism is given by a pair $(\Psi, t)$ where $\Psi: \Theta=\times_{i=0}^{N} \Theta^{i} \rightarrow \Delta^{|K|-1}$ is the allocation rule, and $t: \Theta \rightarrow \Re^{N+1}$ is the payment rule.

We assume below that types are independent. Given a mechanism $(\Psi, t)$, define $\bar{v}^{i}\left(\tau^{i}, \theta^{i}\right)=E_{\theta^{-i}}\left[\Psi\left(\tau^{i}, \theta^{-i}\right) \cdot v^{i}(\theta)\right]$ and $\bar{t}^{i}\left(\tau^{i}\right)=E_{\theta^{-i}}\left[t^{i}\left(\tau^{i}, \theta^{-i}\right)\right]$. Then $U^{i}\left(\tau^{i}, \theta^{i}\right)=$ $\bar{v}^{i}\left(\tau^{i}, \theta^{i}\right)+\bar{t}^{i}\left(\tau^{i}\right)$ represents agent $i^{\prime}$ s expected utility when all other agents report truthfully, and when $i$ has true type $\theta^{i}$ but reports type $\tau^{i}$.

A mechanism $(\Psi, t)$ is incentive compatible if:

$$
\forall i, \theta^{i}, V^{i}\left(\theta^{i}\right) \equiv U^{i}\left(\theta^{i}, \theta^{i}\right)=\sup _{\tau^{i} \in \Theta^{i}} U^{i}\left(\tau^{i}, \theta^{i}\right)
$$

The function $V^{i}\left(\theta^{i}\right)$ represents agent $i$ 's expected utility in a truthful Bayes-Nash equilibrium. There are several versions of characterization results in the literature. The one below is due to Krishna and Maenner $(2001)^{24}$ :

Theorem 8 Assume that, for each $i$, the type set $\Theta^{i}$ is convex and that $u_{i}\left(k, \theta^{-i}, \cdot, t^{i}\right)$ is a convex function of $\theta^{i}$. Then, in any incentive compatible mechanism $(\Psi, t)$, the expected equilibrium utility function $V^{i}\left(\theta^{i}\right)$ is convex, and is determined by the allocation rule $\Psi$ up to an additive constant. For any $\theta^{i}, \tau^{i} \in \Theta^{i}$, and for any smooth

\footnotetext{
${ }^{24}$ Although these authors give an independent proof, it has been pointed to us by Ennio Stacchetti that the integral formula below follows from a known result in convex analysis. See Theorem 2.3.4. in Hiriart-Urruty and Lemarechal C. (2001). For another result that substitutes convexity of the utility function with a differentiability requirement, see Milgrom and Segal (2002).
} 
path $\gamma$ joining $\theta^{i}$ to $\tau^{i}$ in $\Theta^{i}$, it holds that $V^{i}\left(\theta^{i}\right)=V^{i}\left(\tau^{i}\right)+\int q^{i} \cdot d \gamma$ where $q^{i}$ is a subgradient ${ }^{25}$ of $V^{i}$ at $\theta^{i}$.

The main complication added by the presence of multidimensional signals is the requirement that $q^{i}$, which is fully determined by $\Psi$, be a (sub)gradient of a convex function $V^{i}$. Whereas this requirement reduces to a standard monotonicity condition in the one-dimensional case, it involves both a monotonicity condition, and a differential condition on the cross derivatives of $q^{i}$ (yielding the path independence condition) if signals are multidimensional. These consequences of multidimensional constraints in the context of auctions have been first pointed out by Jehiel, Moldovanu, and Stacchetti $(1996,1999) .{ }^{26}$

To get some geometric intuition about the added complexity, consider the following example:

Example 9 There are two objects, $A$ and $B$, and one bidder. The bidder obtains a two-dimensional private signal $\left(v_{A}, v_{B}\right)$ about the values of the two goods. The bundle is worth $v_{A}+v_{B}$.

Any deterministic, incentive compatible mechanism divides the two-dimensional set of types into areas of constant allocation. The gradient of the equilibrium utility is given here by the probabilities with which the bidder gets the objects. Thus, the vector $q$ is either $(0,0),(0,1),(1,0)$ or $(1,1)$. Convexity of $V$ (or, equivalently, monotonicity of $q$ ) implies that, as we increase valuations, $q$ is only allowed to "jump" from $(0,0)$ to either $(0,1),(1,0)$ or $(1,1)$, and from $(0,1),(1,0)$ to $(1,1)$. This is similar to the insight obtained in one-dimensional models. But, there

\footnotetext{
${ }^{25}$ Consider a convex function $F: C \rightarrow \Re$ where $C \subset \Re^{d}$. A vector $x^{*} \in \Re^{d}$ is a subgradient of $F$ at $x \in C$ if for all $y \in C$ it holds: $F(y) \geq x^{*} \cdot(y-x)$. Whenever $F$ is differentiable (a.e.) the subgradient is unique and coincides with the usual gradient.

${ }^{26}$ Analogous results appeared earlier in the monopolistic screening literature (see Rochet, 1985).
} 


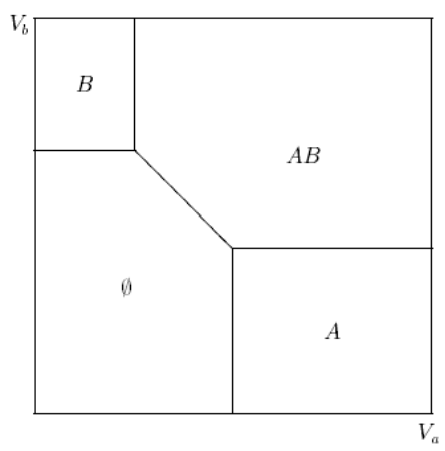

is an additional twist here: if a jump occurs, the integral of $q$ will not depend on the path of integration (i.e., the vector field $q$ is conservative) if and only if "the jump vector" is perpendicular to the boundary between the areas where each alternative is chosen. For example, the boundary between areas where the buyer either gets both objects or none must have a slope of $45^{\circ}$ (since the jump is $(1,1)-(0,0)=(1,1)$ ), while the boundaries between areas where the buyer gets either one object or two are either horizontal, or vertical lines. While here these observations could be derived from the Taxation Principle of monopolistic screening, the analog conditions become very involved in auctions, where there are several interacting agents. The requirement of conservativeness on the vector field $q$ yields partial differential equations that determine boundaries, which need not be straight lines (for these insights and an application, see Jehiel, Moldovanu and Stacchetti, 1999).

An important corollary of Theorem 8 is the so called payoff and revenue equivalence result. Consider two incentive compatible mechanisms $(\Psi, t)$ and $(\Psi, s)$ that implement the same allocation rule $\Psi$, and thus yield the same expressions for $\bar{v}^{i}$ and $q^{i}$. Choose an arbitrary type $\widetilde{\theta}^{i}$, and let $V_{t}^{i}\left(\widetilde{\theta}^{i}\right)$ and $V_{s}\left(\widetilde{\theta}^{i}\right)$ denote the expected equilibrium utility in the truth-telling equilibria of $(\Psi, t)$ and $(\Psi, s)$, respectively. Payoff and revenue equivalence follows immediately from the above Theorem by 
noting that :

$$
\begin{aligned}
& \forall i, \theta^{i}, \bar{t}^{i}\left(\theta^{i}\right)=V_{t}^{i}\left(\widetilde{\theta}^{i}\right)-\bar{v}^{i}\left(\theta^{i}, \theta^{i}\right)+\int q^{i} \cdot d \gamma \\
& \forall i, \theta^{i}, \bar{s}^{i}\left(\theta^{i}\right)=V_{s}^{i}\left(\widetilde{\theta}^{i}\right)-\bar{v}^{i}\left(\theta^{i}, \theta^{i}\right)+\int q^{i} \cdot d \gamma
\end{aligned}
$$

The above equations yield together:

$$
\forall i, \theta^{i}, \bar{t}^{i}\left(\theta^{i}\right)-\bar{s}^{i}\left(\theta^{i}\right)=V_{t}^{i}\left(\widetilde{\theta}^{i}\right)-V_{s}^{i}\left(\widetilde{\theta}^{i}\right)=\mathrm{const}
$$

In other words, expected transfers in the two mechanisms are, up to a constant, the same. Analogous payoff equivalence results for dominant-strategy or ex-post implementation can be proved along similar lines, but these no longer require that the distribution of signals be independent across agents. Moreover, they deliver equivalence up to a constant of actual transfers rather than expected transfers (see, for example, Chung and Ely, 2001).

\subsection{Welfare Maximization}

In this subsection we ask whether the welfare-maximizing rule can be Bayes-Nash implemented. Our main results (Theorems 10 and 11) assert that this is generically impossible when agents have multi-dimensional private information.

Let us first briefly review the classic insight of Vickrey (1961), Clarke (1971), and Groves (1973) for private values auction where each agent $i$ cares only about his own private signal, but may care about the entire partition of objects (thus allocative externalities are permitted).

For the auction application, we assume that $v_{P}^{i}(\theta) \equiv v_{P}^{i}\left(\theta^{i}\right)$. For any profile of signals $\theta$, define $P^{*}(\theta) \in \arg \max _{P \in \mathcal{P}} \sum_{j} v_{P}^{j}\left(\theta^{j}\right)$ to be a welfare-maximizing allocation rule. ${ }^{27}$. Let $P_{-i}$ be a partition of objects where agent $i$ is allocated the

\footnotetext{
${ }^{27}$ If the argmax is not unique, any selection will do.
} 
empty set, and let $\mathcal{P}_{-i}$ denote the set of such partitions. For any profile $\theta^{-i}$ define $P_{-i}^{*}\left(\theta^{-i}\right)=\arg \max _{P_{-i} \in \mathcal{P}_{-i}} \sum_{j \neq i} v_{P_{-i}}^{j}\left(\theta^{j}\right)$ to be the welfare-maximizing partition of objects in the absence of $i$.

The VCG mechanism is the direct revelation mechanism where, for each reported profile of signals $\theta$, the designer implements partition $P^{*}(\theta)=\arg \max _{P \in \mathcal{P}} \sum_{j} v_{P}^{j}\left(\theta^{j}\right)$, and makes a transfer to $i$ given by $t^{i}\left(\theta^{-i}\right)=\sum_{j \neq i} v_{P^{*}(\theta)}^{j}\left(\theta^{j}\right)-\sum_{j \neq i} v_{P_{-i}^{*}\left(\theta^{-i}\right)}^{j}\left(\theta^{j}\right)$.

Truth-telling is a dominant strategy for each player whatever the dimensionality of $\theta^{i}$, and whatever the form of $v^{i}$ because the transfers ensure that each agent's objective is aligned with the welfare criterion. Except in degenerate cases, agents in a VCG mechanism have strictly positive interim incentives to report truthfully because of the uncertainty (still to be resolved at the time of the reporting) about the chosen alternative.

To simply state our impossibility results for frameworks with informational externalities, we consider a linear specification of preferences, and we assume that the designer has no private information. We let $v_{k}^{i}\left(\theta^{1}, \ldots, \theta^{N}\right)=\sum_{j=1}^{N} a_{k i}^{j} \theta_{k i}^{j}$, and assume that $a_{k i}^{i} \geq 0$ for all $k, i$. The signal $\theta^{i}$ of agent $i$ is drawn from a space $\Theta^{i} \subseteq \mathbb{R}^{K \times N}$ according to a continuous density $f_{i}\left(\theta^{i}\right)>0$, independently of other agents' signals $\theta^{-i}$.

Consider a direct revelation mechanism $(\mathrm{DRM})(\Psi, t)$ where $\Psi_{k}\left(\tau^{1}, \ldots \tau^{N}\right)$ is the probability that alternative $k$ is chosen given the report profile $\tau=\left(\tau^{1}, \ldots \tau^{N}\right)$, and $t^{i}\left(\tau^{1}, \ldots \tau^{N}\right)$ is the transfer received by agent $i$ given the report profile $\tau$.

Using the methodology developed for Theorem 8 , let $V^{i}\left(\theta^{i}\right)$ be agent $i^{\prime} s$ expected utility in a truth-telling equilibrium of a direct revelation mechanism:

$$
V^{i}\left(\theta^{i}\right)=U^{i}\left(\theta^{i}, \theta^{i}\right)=\sup _{\tau^{i}} U^{i}\left(\tau^{i}, \theta^{i}\right)
$$

where 


$$
\begin{aligned}
U^{i}\left(\tau^{i}, \theta^{i}\right) & =\sum_{k}\left\{a_{k i}^{i} q_{k}^{i}\left(\tau^{i}\right) \theta_{k i}^{i}+\sum_{j \neq i} a_{k i}^{j} \int_{\Theta^{-i}} \Psi_{k}\left(\tau^{i}, \theta^{-i}\right) f_{-i}\left(\theta^{-i}\right) d \theta^{-i}\right\}+\bar{t}^{i}\left(\tau^{i}\right) \\
q_{k}^{i}\left(\tau^{i}\right) & =\int_{\Theta^{-i}} \Psi_{k}\left(\tau^{i}, \theta^{-i}\right) f_{-i}\left(\theta^{-i}\right) d \theta^{-i}
\end{aligned}
$$

The function $q_{k}^{i}\left(\tau^{i}\right)$ is agent $i^{\prime}$ s equilibrium interim expected probability that alternative $k$ is chosen conditional on $i$ 's report $\tau^{i}$.

Recall that $V^{i}$ is convex, and hence twice continuously differentiable almost everywhere. At such point of differentiability, we obtain by the Envelope Theorem that:

$$
\begin{aligned}
& \frac{\partial V^{i}}{\partial \theta_{k i}^{i}}\left(\theta^{i}\right)=a_{k i}^{i} q_{k}^{i}\left(\theta^{i}\right) \\
& \frac{\partial V^{i}}{\partial \theta_{k j}^{i}}\left(\theta^{i}\right)=0 \text { for } j \neq i
\end{aligned}
$$

By Schwarz's Theorem, the cross derivatives of $V^{i}$ at $\theta^{i}$ must be equal. This implies for all $k, k^{\prime}, i, j \neq i$ :

$$
\begin{aligned}
& a_{k i}^{i} \frac{\partial q_{k}^{i}\left(\theta^{i}\right)}{\partial \theta_{k^{\prime} i}^{i}}=a_{k^{\prime} i}^{i} \frac{\partial q_{k^{\prime}}^{i}\left(\theta^{i}\right)}{\partial \theta_{k i}^{i}} \\
& a_{k i}^{i} \frac{\partial q_{k}^{i}\left(\theta^{i}\right)}{\partial \theta_{k^{\prime} j}^{i}}=0
\end{aligned}
$$

Consider now a welfare-maximizing allocation rule: $\Psi_{k^{*}}\left(\theta^{1}, \ldots \theta^{N}\right)=0$ if $k^{*} \notin$ $\arg \max _{k} \sum_{i=1}^{N} v_{k}^{i}\left(\theta^{1}, \ldots, \theta^{N}\right)$. For such rules we can directly compute the induced interim expected probabilities that each alternative is chosen. The impossibility result is obtained by showing that these functions cannot generically satisfy (2) and (3):

Theorem 10 (Jehiel-Moldovanu 2001) Let $(\Psi, t)$ be a welfare maximizing DRM, and assume that the following conditions are satisfied. (1) There exist $i, j, k$ such 
that $i \neq j, a_{k i}^{i} \neq 0$ and $a_{k j}^{i} \neq 0$. (2) There exists an open set of $\theta^{i}$ such that, depending on the realization of $\theta^{-i}$, the welfare maximizing alternative is either $k$ or $k^{\prime}$. Then $(\Psi, t)$ cannot be incentive compatible.

Proof. Conditions 1 and 2 ensure that, for an open set of signals $\theta^{i}$, the interim expected probabilities (that each alternative is chosen) induced by any value maximizing DRM must satisfy $\partial q_{k}^{i}\left(\theta^{i}\right) / \partial \theta_{k j}^{i} \neq 0$. This is incompatible with (3).

For the proof we have only used identities (3). This is enough because the signal $\theta^{i}$ of agent $i$ has dimension $N \times K$, which, in particular, is larger than the dimension of the alternatives $K$. The above result is not too surprising, as it seems impossible to elicit an information that has more dimensions than the number of alternatives the agent cares about. Maskin (1992) provided an early example with this flavor, but he used the stronger ex-post equilibrium concept.

It is important to understand what happens to the impossibility result if the dimension of the signals is no larger than $K$, the number of payoff-relevant alternatives, i.e., when the simple insight obtained above does not necessarily hold. Consider the same setting as above, except that agent $i$ receives a $K$-dimensional signal ${ }^{28}$ $\theta^{i}=\left(\theta_{k}^{i}\right)$ and $v_{k}^{i}\left(\theta^{1}, \ldots, \theta^{N}\right)=\sum_{j=1}^{N} a_{k i}^{j} \theta_{k}^{j}$. Identities (2) become now:

$$
\forall i, k, k^{\prime} \neq k, a_{k i}^{i} \frac{\partial q_{k}^{i}\left(\theta^{i}\right)}{\partial \theta_{k^{\prime}}^{i}}=a_{k^{\prime} i}^{i} \frac{\partial q_{k^{\prime}}^{i}\left(\theta^{i}\right)}{\partial \theta_{k}^{i}}
$$

Theorem 11 (Jehiel-Moldovanu 2001) Let $(\Psi, t)$ be a welfare maximizing DRM, and assume that the following conditions are satisfied: (1) There exist $i, k$ and $k^{\prime}$ such that $a_{k^{\prime} i}^{i} \neq 0$. (2) There exists an open set of $\theta^{i}$ such that, depending on the realization of $\theta^{-i}$, the welfare maximizing alternative is either $k$ or $k^{\prime}$. Then, if $(\Psi, t)$ is Bayes-Nash incentive compatible, it must be the case that:

$$
\frac{a_{k i}^{i}}{a_{k^{\prime} i}^{i}}=\frac{\sum_{j=1}^{N} a_{k j}^{i}}{\sum_{j=1}^{N} a_{k^{\prime} j}^{i}}
$$

\footnotetext{
${ }^{28}$ That is, from the viewpoint of the above more general model, we assume that $\theta_{i k}^{j}=\theta_{k}^{j}$.
} 
Proof. The result follows from the observation that a welfare-maximizing DRM must satisfy

$$
\sum_{j=1}^{N} a_{k j}^{i} \frac{\partial q_{k}^{i}\left(\theta^{i}\right)}{\partial \theta_{k^{\prime}}^{i}}=\sum_{j=1}^{N} a_{k^{\prime} j}^{i} \frac{\partial q_{k^{\prime}}^{i}\left(\theta^{i}\right)}{\partial \theta_{k}^{i}}
$$

To see this, consider a setting where all agents' preferences coincide with total welfare. If a DRM chooses the welfare maximizing alternative (without any transfer), every agent has obviously an incentive to report truthfully. Thus, conditions (4) must be satisfied for such preferences, yielding (6). In other words, condition (6) must hold for the interim expected probabilities generated by any mechanism that chooses the welfare-maximizing alternative! But, the incentive constraints (with respect to the original preferences) imply conditions (4). Combining (4) and (6) we get $(5)$.

Since the above formulation is relatively abstract, it is helpful to consider a simple auction example:

Example 12 There are two objects $A$ and $B$, and two bidders $i=1,2$. Each bidder $i$ receives a signal ${ }^{29} \theta^{i}=\left(\theta_{A}^{i}, \theta_{B}^{i}\right)$. Bidder $i$ 's valuations (which depend only on $i$ 's bundle) are given by: $v_{X}^{i}(\theta)=\theta_{X}^{i}+a_{X i}^{-i} \theta_{X}^{-i}, \quad X=A, B ; \quad v_{A B}^{i}(\theta)=v_{A}^{i}(\theta)+v_{B}^{i}(\theta)+$ $s_{A B}^{i}$. We refer to $s_{A B}^{i}$ as $i$ 's synergy term, and assume that these terms are common knowledge.

Consider a direct truthful mechanism with associated interim expected probabilities $q_{P}^{i}\left(\theta^{i}\right)$, where the partition $P=P_{i j}$, denotes the allocation where object $A$ is allocated to agent $i$ and object $B$ to agent $j$ (thus $P_{i i}$ denotes the allocation where $i$ gets both objects, and so on..). At points of twice continuous differentiability (a.e.),

\footnotetext{
${ }^{29}$ Note that every bidder receives a signal of lower dimension than the the number of partitions, or even than the number of bundles he cares about.
} 
we obtain by the Envelope Theorem that:

$$
\begin{gathered}
\frac{\partial V^{i}}{\partial \theta_{A}^{i}}\left(\theta^{i}\right)=q_{P_{i i}}^{i}\left(\theta^{i}\right)+q_{P_{i j}}^{i}\left(\theta^{i}\right) ; \frac{\partial V^{i}}{\partial \theta_{B}^{i}}\left(\theta^{i}\right)=q_{P_{i i}}^{i}\left(\theta^{i}\right)+q_{P_{j i}}^{i}\left(\theta^{i}\right) \\
\frac{\partial}{\partial \theta_{B}^{i}}\left[q_{P_{i i}}^{i}\left(\theta^{i}\right)+q_{P_{i j}}^{i}\left(\theta^{i}\right)\right]=\frac{\partial}{\partial \theta_{A}^{i}}\left[q_{P_{i i}}^{i}\left(\theta^{i}\right)+q_{P_{j i}}^{i}\left(\theta^{i}\right)\right]
\end{gathered}
$$

Consider now the welfare-maximizing allocation rule, and let $\widetilde{q}_{P}^{i}\left(\theta^{i}\right)$ denote the expected probability that the partition $P$ is chosen conditional on $i$ 's signal $\theta^{i}$. Since such an allocation can be implemented whenever agents' preferences coincide with total welfare, $\widetilde{q}$ must satisfy:

$$
\frac{\partial}{\partial \theta_{B}^{i}}\left[\widetilde{q}_{P_{i i}}^{i}+\widetilde{q}_{P_{i j}}^{i}+a_{A j}^{i} \widetilde{q}_{P_{j i}}^{i}+a_{A j}^{i} \widetilde{q}_{P_{j j}}^{i}\right]\left(\theta^{i}\right)=\frac{\partial}{\partial \theta_{A}^{i}}\left[\widetilde{q}_{P_{i i}}^{i}+\widetilde{q}_{P_{j i}}^{i}+a_{B j}^{i} \widetilde{q}_{P_{i j}}^{i}+a_{B j}^{i} \widetilde{q}_{P_{j j}}^{i}\right]\left(\theta^{i}\right)
$$

Unless $a_{A j}^{i}=a_{B j}^{i}=0$, (i.e., unless there are no informational externalities) equations (7) and (8) are not compatible. To see that, assume for concreteness that the partition $P_{j j}$ is never welfare-maximizing (say, because $s_{A B}^{j}$ is negative with a large absolute value), and assume that $a_{B j}^{i}=0$ while $a_{A j}^{i}>0$. Then $\widetilde{q}_{P_{j j}}^{i}=0$, and it is readily verified that (7) and (8) are incompatible because $\frac{\partial}{\partial \theta_{B}^{i}} \widetilde{q}_{P_{j i}}^{i} \neq 0$ whenever ${ }^{30}$ $\frac{\partial}{\partial \theta_{B}^{i}}\left[\widetilde{q}_{P_{i i}}^{i}+\widetilde{q}_{P_{i j}}^{i}+a_{A j}^{i} \widetilde{q}_{P_{j i}}^{i}\right]=\frac{\partial}{\partial \theta_{A}^{i}}\left[\widetilde{q}_{P_{i i}}^{i}+\widetilde{q}_{P_{j i}}^{i}\right]$.

In some non-generic cases, the welfare-maximizing allocation rule can be implemented even when there are informational externalities. This is, for example, the case when $s_{A B}^{i}=0, i=1,2$ and when $a_{X i}^{-i}<1, X=A, B, i=1,2$. Given the separability of the problems in this case, the efficient allocation takes the form:

$$
\begin{aligned}
& q_{P_{i i}}^{i}\left(\theta^{i}\right)=q_{A}^{i}\left(\theta_{A}^{i}\right) q_{B}^{i}\left(\theta_{B}^{i}\right) ; \quad q_{P_{i j}}^{i}\left(\theta^{i}\right)=q_{A}^{i}\left(\theta_{A}^{i}\right)\left[1-q_{B}^{i}\left(\theta_{B}^{i}\right)\right] \\
& q_{P_{j i}}^{i}\left(\theta^{i}\right)=\left[1-q_{A}^{i}\left(\theta_{A}^{i}\right)\right] q_{B}^{i}\left(\theta_{B}^{i}\right) ; \quad q_{P_{j j}}^{i}\left(\theta^{i}\right)=\left[1-q_{A}^{i}\left(\theta_{A}^{i}\right)\right]\left[1-q_{B}^{i}\left(\theta_{B}^{i}\right)\right]
\end{aligned}
$$

where $q_{X}^{i}\left(\theta_{X}^{i}\right)$ denotes the interim expected probability that good $X$ is allocated to $i$ conditional on $\theta_{X}^{i}$. Conditions (7) and (8) are always met for such separable

\footnotetext{
${ }^{30}$ For example, if the synergy term $s_{A B}^{i}$ is non-positive, and if partition $P_{j i}$ is sometimes welfare maximizing, one gets $\frac{\partial}{\partial \theta_{B}^{i}} \widetilde{q}_{P_{j i}}^{i}>0$.
} 
allocation functions, no matter what $a_{X j}^{i}$ are ${ }^{31}$, and the welfare-maximizing rule can be implemented using separate, one dimensional second-price auctions.

To sum up, welfare-maximizing is impossible in auctions with interdependent values and multidimensional signals ${ }^{32}$ except in cases where the allocation problem can be divided in separate one-object, one-dimensional auctions. Such a separation is usually impossible if there are complementarities/substitutabilities and/or allocative externalities $^{33}$.

\subsubsection{Possibility Results and Applications}

One-dimensional signals: For a two-bidder, one-object auction with interdependent values Maskin (1992) has shown that welfare maximization can be achieved if both bidders have a one-dimensional signal, and if a single crossing condition holds. This observation has been extended to other one-dimensional settings. Krishna (2003) derives conditions (stronger than single-crossing) ensuring the efficiency of the English ascending auction even if there are more bidders. Kirchkamp and Moldovanu (2004) experimentally compare the performance of the English and second-price sealed-bid auctions with interdependent valuations: as predicted by theory, the English auction is superior from an efficiency point of view. Dasgupta and Maskin (2000), Perry and Reny (2002) and Ausubel (2004) present welfare-maximizing bid-

\footnotetext{
${ }^{31}$ The requirement that $a_{X j}^{i}<1$ is derived from the standard one-dimensional incentive compatibility condition that an agent with a higher signal should receive the good with a higher probability.

${ }^{32}$ This result applies to the the design of private industries. If firms hold multi-dimensional private information (say on fixed and marginal cost), then it is impossible to induce a welfare maximizing market structure even if there are no costs to public funds. This is illustrated in Jehiel and Moldovanu (2004), and contrasts the analysis of Dana and Spier (1994), Auriol and Laffont (1992), and McGuire and Riordan (1995).

${ }^{33}$ Jehiel, Moldovanu and Stacchetti (1996) contains an early impossibility result in a one-object auction with allocative externalities, interdependent values and multidimensional signals.
} 
ding schemes for multi-object auctions where agents have one-dimensional signals.

Within the above described linear model, we provide now a condition ensuring that welfare maximization can be obtained when each agent $i$ receives a one dimensional signal $\theta^{i} \in \Re$, and $i$ 's value of alternative $k$ is given by $v_{k}^{i}\left(\theta^{1}, \ldots, \theta^{N}\right)=$ $\sum_{j=1}^{N} a_{k i}^{j} \theta^{j}$

Theorem 13 (Jehiel and Moldovanu 2001) Suppose that for all $i, k, k^{\prime}, \quad a_{k i}^{i} / a_{k^{\prime} i}^{i}>$ $1 \Rightarrow\left(\sum_{j=1}^{N} a_{k j}^{i}\right) / \sum_{j=1}^{N} a_{k^{\prime} j}^{i}>1$. Then there exists a welfare-maximizing, Bayesian incentive compatible mechanism.

The set of parameters for which welfare maximization can be achieved is now an open set, and it has positive measure. The fundamental difference is due to the incentive constraints that now reduce to a simple monotonicity condition (without the complex integrability requirement). The relevant mechanism for the above result follows the Vickrey-Clarke-Groves logic by completely dampening the influence of one's own signal on one's own transfer.

Gresik (1991), Fieseler, Kittsteiner and Moldovanu (2003), Kittsteiner (2003), Jehiel and Pauzner (2004), Ornelas and Tuner (2004) and Brusco, Lopomo, and Wiswanathan (2004) analyze properties of trading models with interdependent values and one-dimensional signals in a variety of settings that combine features of the classical models due to Akerlof (1970), Myerson-Satterthwaite (19831) and CramtonGibbons-Klemperer (1987). For example, Fieseler et al. (2003) show that negative (positive) informational externalities make it easier (harder) to construct welfaremaximizing, budget balanced and individual-rational mechanisms than in analogous cases with private values. Jehiel and Pauzner (2005) show that extreme ownership structures may dominate mixed ownerships in partnership dissolution setups with interdependent values and one-sided private information. 
Hain and Mitra (2004) and Kittsteiner and Moldovanu (2005) analyze scheduling and queueing problems, respectively, where agents have private information about processing times: this naturally yields a model with informational externalities since waiting costs depend on information available to others. Gruener and Kiel (2004) focus on collective decisions with interdependent values in the absence of monetary transfers. Finally, Bergemann and Valimaki (2002) focus on the incentives for information acquision with interdependent values.

Correlated signals Our impossibility results (Theorems 10 and 11) assumed that the signals are independently distributed across agents. If the signals held by various agents are correlated, it is possible to design subtle transfer devices whereby the belief held by agent $i$ on the signal of agent $j$ is elicited for free. When $j$ 's belief about $i$ 's signal completely determines the signal held by $i^{34}$, a welfare-maximizing allocation can be (approximately) implemented, using the logarithmic scoring rule used in Johnson et al. (1990) and Johnson et al. (2003). It is important to note that the approach developed by Cremer-McLean $(1985,1988)$ is not useful ${ }^{35}$ here since it relies on the existence of a welfare-maximizing mechanism. As shown above, this fails if there are informational externalities and multidimensional signals.

To illustrate Johnson et al.'s idea, suppose that agent $j$ believes that $i$ 's signal is distributed according to the density $\beta\left(\theta^{i}\right)$, and that agent $j$ is asked to report her belief to a designer who observes the realization of $\theta^{i}$ (in equilibrium this will be reported by $i$ ). Suppose further that (up to a constant) agent $j$ receives $\ln \widetilde{\beta}\left(\theta^{i}\right)$ conditional on $\theta^{i}$, where $\widetilde{\beta}$ is the report made by $j$ about $\beta^{36}$. Agent $j$ will optimally

\footnotetext{
${ }^{34}$ In two recent papers, Neeman (2004) and Heifetz and Neeman (2005) challenge the view that, generically, there is a one-to one mapping from $j$ 's belief onto $i$ 's type in the correlated case.

${ }^{35}$ McLean and Postelwaite (2004) use this approach, but only for situations where agents are informationally small.

${ }^{36} \mathrm{We}$ assume (for now) that the report made by $j$ is not used to implement a social alternative.
} 
choose to report her true belief because $\int \beta\left(\theta^{i}\right) \ln \widetilde{\beta}\left(\theta^{i}\right) d \theta^{i} \leq \int \beta\left(\theta^{i}\right) \ln \beta\left(\theta^{i}\right) d \theta^{i} \Leftrightarrow$ $\int \beta\left(\theta^{i}\right) \ln \frac{\widetilde{\beta}\left(\theta^{i}\right)}{\beta\left(\theta^{i}\right)} d \theta^{i} \leq 1$ and because $\int \beta\left(\theta^{i}\right) \ln \frac{\widetilde{\beta}\left(\theta^{i}\right)}{\beta\left(\theta^{i}\right)} d \theta^{i} \leq \ln \left(\int \beta\left(\theta^{i}\right) \frac{\widetilde{\beta}\left(\theta^{i}\right)}{\beta\left(\theta^{i}\right)} d \theta^{i}\right)=0$ by the concavity of the logarithm, and by $\int \widetilde{\beta}\left(\theta^{i}\right) d \theta^{i}=1$.

The welfare-maximizing allocation can be now (approximately) implemented whenever there is a one-to-one mapping from $j$ 's belief onto $i$ 's signal: by having a transfer that puts a sufficiently large weight on $\ln \widetilde{\beta}\left(\theta^{i}\right)$, agent $j$ will have the right incentive to report her true belief on $i$ 's signal (the belief being isomorphic to her type). This result does not rely on the form of the preferences, and it is solely driven by the facts that different types correspond to different beliefs, and that beliefs can be elicited for free when there is no restriction on the size of the transfers. Arbitrarily large transfers (via the weight on $\ln \widetilde{\beta}\left(\theta^{i}\right)$ ) are required whenever distributions of types are almost independent across agents. If bounds on transfers are imposed (because, say, of limited liability constraints) our impossibility result persists whenever the distribution of signals is not too far from the independent case.

Conditioning on extra information: Mezzetti (2004) considers a different informational environment. After the social alternative has been chosen, and before monetary payments have been concluded, the agents observe their payoff from the chosen alternative ${ }^{37}$. Thus, agents receive information in addition to their initial signals. Mezzetti observes that an efficient mechanism can be implemented in two stages: In stage 1, agents report their signals; based on the reports, the value maximizing alternative is implemented. In stage 2, transfers are implemented according to a VCG mechanism based on reports about the observed payoffs in the alternative chosen at stage 1. Mezzetti's insight is valuable, but the proposed mechanism suffers from a number of serious drawbacks. First, at stage 2, agents are completely

\footnotetext{
${ }^{37}$ Hansen (1985) is an early paper on auction with contingent payments in settings where additional information becomes available.
} 
indifferent about their announcement, since it only serves to compute the transfers received by others. This is in sharp contrast with the agents' strictly positive incentive (due to the unresolved uncertainty about the chosen alternative) to report their true types in the VCG mechanism in the private values case. Second, in many applications, a significant amount of time may elapse before the payoff attached to a chosen alternative is revealed to an agent. Then, allowing for transfers that are contingent on information that becomes available in a distant future seems impractical $^{38}$.

\subsection{Ex-post Implementation without Welfare Maximization}

Bayesian mechanism design has been criticized on the ground that both the designer and the agents need a lot of information about the distribution of the private signals in order to choose their best course of action. ${ }^{39}$ Robust implementation seeks for a stronger notion of implementation where the agents and the designer do not need such precise information. In private value contexts, this leads to dominant strategy implementation, whereas the analogous concept for settings with informational externalities is ex-post implementation ${ }^{40}$ : Agents should find it optimal to report their true signals even after learning the signals received by others. Such a notion is necessary for robustness since, in particular, implementation should be possible for the degenerate belief that other agents' signals are given by a specific realization. It

\footnotetext{
${ }^{38}$ This pertains also to the lemons market. Mezzetti's philosophy suggests that there is no problem for a buyer and a seller to agree on price after the buyer observes quality (say after one year of driving a used car). In our opinion, such mechanisms are fragile due to the noisy and subjective assessments of quality, moral hazard, verifiability, etc....

${ }^{39}$ This is sometimes referred to as Wilson's critique.

${ }^{40}$ This notion corresponds to the uniform equilibrium first defined by d'Aspremont and Gerard Varet (1979), and to uniform incentive compatibility as defined by Holmstrom and Myerson (1983). The term ex-post equilibrium is due to Cremer and McLean (1985).
} 
is also sufficient in quasi-linear environments since ex-post implementation requires that, whatever their beliefs about others' types, agents find it optimal to report their true types whenever other agents are expected to report truthfully. These ideas have been recently formalized by Bergemann and Morris (2005). ${ }^{41}$

An immediate corollary of the main result in subsection 4.2 is that, generically, the welfare-maximizing allocation cannot be robustly implemented if there are multidimensional signals and informational externalities (if it were, welfare-maximizing Bayes-Nash implementation would be possible for any prior, including the independent case; but this was shown to be false!)

It turns out that, for generic valuation functions, no deterministic social rule that makes use of the agents' reports can be ex post implemented. To state formally this result, consider choice functions $\psi: S \rightarrow K$, with the property that there are transfers functions $t^{i}: S \rightarrow \mathbb{R}$, such that truth-telling is an ex-post equilibrium in the incomplete information game that is induced by the direct revelation mechanism $\left(\psi,\left(t^{i}\right)_{i \in N}\right)$, i.e.

$$
v_{\psi(\theta)}^{i}(\theta)+t^{i}(\theta) \geq v_{\psi\left(\tilde{\theta}^{i}, \theta^{-i}\right)}^{i}(\theta)+t^{i}\left(\widetilde{\theta}^{i}, \theta^{-i}\right)
$$

for all $\theta^{i}, \widetilde{\theta}^{i} \in \Theta^{i}$ and $\theta^{-i} \in \Theta^{-i}$. Such a choice rule $\psi$ is said to be ex post implementable. We call a choice function $\psi$ trivial if it is constant on the interior $\Theta$ of the type space.

By requiring optimality of $i$ 's truth-telling for every realization of other agents types $\theta^{-i}$, inequality (9) treats $\theta^{-i}$ as if it was known to agent $i$. Her incentive constraint is thus equivalent to a monopolistic screening problem for every $\theta^{-i}$. Thus, the designer can post personalized prices $p_{k}^{i}\left(\theta^{-i}\right)$ for the various alternatives, and let the individuals choose among them. In equilibrium all agents must agree on a most favorable alternative:

\footnotetext{
${ }^{41}$ See also Dasgupta, Hammond, Maskin, (1979) and Ledyard (1978) for early, related arguments in private value frameworks.
} 
Lemma 14 (Ex-Post Taxation Principle) A choice function $\psi$ is ex post implementable, if and only if for all $i \in \mathcal{N}, k \in \mathcal{K}$ and $s^{-i} \in S^{-i}$, there are transfers $\left(p_{k}^{i}\left(\theta^{-i}\right)\right)_{k} \in(\mathbb{R} \cup\{\infty\})^{N} \backslash(\infty, \ldots, \infty)$ such that:

$$
\psi(\theta) \in \arg \max _{k \in \mathcal{K}}\left\{v_{k}^{i}(\theta)-p_{k}^{i}\left(\theta^{-i}\right)\right\} .
$$

The difficulty of finding an ex-post implementable rule is that (10) should be simultaneously satisfied for all agents $i$.

To illustrate our impossibility result, we now reduce the problem by assuming that there are only two agents, $i=1,2$ and two alternatives $k, l$. Because agents' incentives are only responsive to differences in payoffs, it is convenient to focus on relative valuations ${ }^{42} \mu^{i}$ and relative prices $\delta^{i}$ :

$$
\mu^{i}(\theta)=v_{k}^{i}(\theta)-v_{l}^{i}(\theta) ; \delta^{i}\left(\theta^{-i}\right)=p_{k}^{i}\left(\theta^{-i}\right)-p_{l}^{i}\left(\theta^{-i}\right)
$$

Assuming, that relative prices $\delta$ are continuous, the taxation principle implies that at a signal $\theta$ such that agent $i$ is indifferent between the two alternatives, agent $j$ should also be indifferent (since they agree on the preferred alternative). That is,

$$
\mu^{i}(\theta)-\delta^{i}\left(\theta^{-i}\right)=0 \Leftrightarrow \mu^{j}(\theta)-\delta^{j}\left(\theta^{-j}\right)=0
$$

Assuming further that relative prices $\delta$ are differentiable, condition (11) implies that the gradients of agents's payoff functions must be parallel on the indifference set (i.e., the set of signal profile where agents are indifferent between the two alternatives). That is,

$$
\left(\begin{array}{c}
\nabla_{\theta^{i}} \mu^{i}(\theta) \\
\nabla_{\theta^{-i}} \mu^{i}(\theta)-\nabla_{\theta^{-i}} \delta^{i}\left(\theta^{-i}\right)
\end{array}\right) \text { and }\left(\begin{array}{c}
\nabla_{\theta^{i}} \mu^{-i}(\theta)-\nabla_{\theta^{i}} \delta^{-i}\left(\theta^{i}\right) \\
\nabla_{\theta^{-i}} \mu^{-i}(\theta)
\end{array}\right)
$$

are parallel on the indifference set. For differentiable relative price functions, this implies:

\footnotetext{
${ }^{42}$ For technical simplicity, we assume that relative valuations satisfy the mild requirement $\nabla_{\theta^{i}} \mu^{i}(\theta) \neq 0$ for all $\theta \in \Theta$.
} 
Proposition 15 (Jehiel et al. 2005) Let $(\psi, t)$ be a non-trivial ex-post incentive compatible mechanism. If the relative transfers $\delta^{i}$ are differentiable for all $i \in\{1,2\}$ then, there exist an indifference signal profile $\widehat{\theta}$, and a vector $y$ (with the dimensionality of $\left.\theta^{i}\right)$ such that $\nabla_{\theta^{i}} \mu^{i}(\theta)$ and $\left(\nabla_{\theta^{i}} \mu^{-i}(\theta)-y\right)$ are parallel for every indifference signal profile $\theta=\left(\widehat{\theta}^{i}, \theta^{-i}\right)$.

Jehiel et al. (2005) extend the above intuition to the case where the relative price function is neither differentiable, nor continuous. This yields:

Theorem 16 (Jehiel et al. 2005) Assume that the dimension of the signal $\theta^{i}$ is at least two for each agent $i=1,2$. Then, for generic preferences ${ }^{43}$, only trivial social choice rules are ex-post implementable.

As an illustration, consider a setting with bilinear valuations and two-dimensional signals $\theta^{i}=\left(\theta_{k}^{i}, \theta_{l}^{i}\right) \in[0,1]^{2}$.

Example 17 Define valuations $v$ by:

$$
\begin{aligned}
& v_{k}^{i}(\theta)=a_{k}^{i} \theta_{k}^{i}+b_{k}^{i} \theta_{k}^{i} \theta_{k}^{-i}=\theta_{k}^{i}\left(a_{k}^{i}+b_{k}^{i} \theta_{k}^{-i}\right) \\
& v_{l}^{i}(\theta)=a_{l}^{i} \theta_{l}^{i}+b_{l}^{i} \theta_{l}^{i} \theta_{l}^{-i}=\theta_{l}^{i}\left(a_{l}^{i}+b_{l}^{i} \theta_{l}^{-i}\right)
\end{aligned}
$$

where $a_{k}^{i}, b_{k}^{i}, a_{l}^{i}, b_{l}^{i} \neq 0$. Thus, $\mu^{i}(\theta)=a_{k}^{i} \theta_{k}^{i}-a_{l}^{i} \theta_{l}^{i}+b_{k}^{i} \theta_{k}^{i} \theta_{k}^{-i}-b_{l}^{i} \theta_{l}^{i} \theta_{l}^{-i}$.

For a vector $y=\left(y_{k}, y_{l}\right)^{T}$ we have

$$
\nabla_{\theta^{i}} \mu^{i}(\theta)=\left(\begin{array}{c}
a_{k}^{i}+b_{k}^{i} \theta_{k}^{-i} \\
-a_{l}^{i}-b_{l}^{i} \theta_{l}^{-i}
\end{array}\right) ;\left(\nabla_{\theta^{i}} \mu^{-i}(\theta)-y\right)=\left(\begin{array}{c}
b_{k}^{-i} \theta_{k}^{-i}-y_{k} \\
-b_{l}^{-i} \theta_{l}^{-i}-y_{l}
\end{array}\right)
$$

It is readily verified that $b_{l}^{1} b_{k}^{2}-b_{k}^{1} b_{l}^{2}=0$ is necessary for such vectors to remain parallel when we vary $\theta_{k}^{-i}$ and $\theta_{l}^{-i}$. It follows from Proposition 15 that a non-trivial choice function $\psi$ is implementable only if $b_{l}^{1} b_{k}^{2}-b_{k}^{1} b_{l}^{2}=0$. The above condition is

\footnotetext{
${ }^{43}$ The result holds both for topological and measure-theoretic notions of genericity
} 
obviously non-generic: the set of parameters where it is satisfied has zero Lebesguemeasure in the 8-dimensional space of coefficients that parameterize the bi-linear valuations in this example.

The impossibility result of Theorem 16 should be contrasted with an elegant result due to Roberts (1979). Roberts requires that each agent $i$ gets a one-dimensional signal for each social alternative ${ }^{44}$. Applied to auctions, this means $\theta^{i}=\left(\theta_{P}^{i}\right)_{P \in \mathcal{P}}$, where $\theta_{P}^{i} \in \Re$, and $v_{P}^{i}(\theta) \equiv v_{P}^{i}\left(\theta_{P}^{i}\right)$. He also assumes that 1$)$ There are at least 3 relevant partitions, and 2) For any $x \in \Re^{|\mathcal{P}|}$ there exists $\theta^{i}=\left(\theta_{P}^{i}\right)_{P \in \mathcal{P}} \in \Theta^{i}$ such that $\left\{v_{P}^{i}\left(\theta_{P}^{i}\right)\right\}_{P \in \mathcal{P}}=x$. With these assumptions, Roberts shows that a deterministic social choice function $\Psi$ is dominant strategy implementable only if there is a set of real weights $\left\{\alpha_{i}\right\}_{i=1,2, . . N}$, not all equal to zero, and a set of real weights $\left\{\lambda_{P}\right\}_{P \in \mathcal{P}}$ such that $P^{\lambda}(\theta)=\arg \max _{P \in \mathcal{P}}\left[\sum_{j} \alpha^{j} v_{P}^{j}\left(\theta_{P}^{j}\right)+\lambda_{P}\right]$.

Thus, dominant strategy implementable social choice functions must maximize a weighted average of the agents values, augmented by a partition-specific weight. Jehiel et al. (2004) call these functions affine maximizers. The "rich preference space" condition 2 above $^{45}$ implies that agents must care about the entire partition of goods. Thus, there must be allocative externalities for Roberts' characterization to hold.

\subsubsection{Possibility results}

We now review several situations that allow for non-trivial ex-post implementation. In all cases, the geometric condition of Proposition 15 is less restrictive.

1) Theorem 16 heavily relies on the impossibility of simultaneously satisfying the

\footnotetext{
${ }^{44}$ This last assumption can be relaxed. See Jehiel et. al. (2004).

${ }^{45}$ Bickchandani et al. (2004), Gui et al. (2004) and Lavi et al. (2004) characterize dominantstrategy implementability on restricted domains where condition 2 need not hold.
} 
incentive constraints of several agents. If there is only one strategic agent, non-trivial ex post implementation is possible ${ }^{46}$.

2) If all agents have a one-dimensional signal ${ }^{47}$, or if only one agent has a multidimensional signal then non-trivial ex post implementation is possible for some open set of preferences (see Jehiel et al. 2005).

3) Consider preferences $v_{k}^{i}(\theta)$ that are additively separable, i.e. $v_{k}^{i}(\theta)=f_{k}^{i}\left(\theta^{i}\right)+$ $h_{k}^{i}\left(\theta^{-i}\right)$. It is readily verified by the standard VCG analysis that $\arg \max _{k} \sum_{i} f_{k}^{i}\left(\theta^{i}\right)$ can be ex-post implemented. Under some technical conditions, only such affine maximizers can be implemented (see Jehiel, Meyer-ter-Vehn and Moldovanu, 2004). This is the counterpart to Roberts' (1979) result in the private values case.

4) Another non generic but interesting class is studied by Bikchandani (2004). He considers a one-object auction without allocative externalities and observes that, by not selling the object for a sufficiently large subset of signals, a non-trivial (yet very inefficient) choice rule can be ex-post implemented.

\section{Conclusion}

We have studied the effects of allocative and informational externalities in auctions and related mechanisms. Because values become endogenous, standard auctions cease to be welfare maximizing in the presence of allocative externalities, and they give rise to a wealth of new phenomena. But the traditional Vickrey-Clarke-Groves mechanisms achieve welfare maximization in such frameworks, as long as there are no informational externalities. Informational externalities can be satisfactorily dealt with only in settings where signals are one-dimensional (and where a single-crossing

\footnotetext{
${ }^{46}$ This should be contrasted with the impossibility of efficient Nash-Bayes implementation, which holds as soon as at least one agent has multidimensional private information.

${ }^{47}$ In this case, the geometric condition merely requires that some scalars (rather than vectors) are multiples of each other
} 
property holds). For example, an English ascending auction is welfare maximizing in one-object symmetric settings, and generalized Vickrey-Clarke-Groves mechanisms are welfare- maximizing even in asymmetric settings as long as signals are scalars. The situation drastically changes when information is multidimensional (as required by general multi-object applications): VCG mechanisms have no analogues, and robust implementation does not allow the use of private information.

We have tried to show that externalities naturally arising in many applications have a significant effect on the outcome of auctions and other mechanisms. From an empirical viewpoint, it is now time to investigate the role (magnitude and effect on bidding strategies) of allocative externalities in auctions - this could parallel the exciting recent work on common value auctions (see Athey and Haile, 2005).

From a theoretical viewpoint, the above analysis leaves open a number of important questions. In particular, since informational externalities make it impossible to implement the welfare-maximizing allocation, how does the second-best allocation look like in such contexts? Since ex-post implementation is generally impossible with informational externalities, what is a good way to achieve robust implementation?

\section{References}

Akerlof, G. (1970): "The Market for Lemons: Quality Uncertainty and the Market Mechanism," Quarterly Journal of Economics 89, 488-500.

Armstrong, M. (1996): "Multiproduct Nonlinear Pricing," Econometrica 64, $51-76$.

d'Aspremont, C., and L.A. Gerard-Varet (1979): "Incentives and Incomplete Information", Journal of Public Economics 11, 25-45.

Athey, S. and P. Haile (2005): "Empirical Models of Auctions", this volume.

Auriol, E. and J-J. Laffont (1992): "Regulation by Duopoly," Journal of Economics and Management Strategy 1, 507-533.

Ausubel, L. (2004): "An Efficient Ascending-Bid Auction for Multiple Objects," 
American Economic Review 94, 1452-1475.

Ausubel L., Milgrom P. (2002) "Ascending Auctions with Package Bidding", Frontiers of Theoretical Economics 1, 1-42.

Bagwell, K., P. Mavroidis and R. Staiger (2004) "The Case for Auctioning Countermeasures in the WTO" , discussion paper, Columbia University

Bergemann, D. and S. Morris (2005): "Robust Mechanism Design", Econometrica 73, 1521-1534.

Bergemann, D. and J. Välimäki (2002): "Information Acquisition and Efficient Mechanism Design", Econometrica 70, 100\%-10035.

Bikhchandani, S. (2004): "The Limits of Ex Post Implementation Revisited," mimeo, UCLA.

Bikchchandani, S., Chatterji, S., and Sen, A. (2004):" Incentive Compatibility in Multi-Unit Auctions", discussion paper UCLA.

Brocas, I. (2003) "Endogenous Entry in Auctions with Negative Externalities", Theory and Decision 54, 125-149.

Brusco, S., G. Lopomo, and S. Wiswanathan (2004): "Merger Mechanisms", mimeo, SUNY, Stony Brook.

Burguet, F. and J. Sempere (2005): "Trade Permits for Greenhouse Emissions", discussion paper, UAB, Barcelona.

Caillaud, B. and P. Jehiel (1998): "Collusion in Auction with Externalities," Rand Journal of Economics 29, 680-702.

Chung, K-S. and J. Ely (2001): "Ex-post Incentive Compatible Mechanism Design", discussion paper, Northwestern University.

Clarke E. (1971): "Multipart Pricing of Public Goods", Public Choice 8, 19-33.

Coase, R. H. (1960): "The Problem of Social Cost," Journal of Law and Economics 3, 1-44.

Compte, O. and P. Jehiel (2002a): "On the value of competition in procurement 
auctions", Econometrica 70, 343-355.

Compte, O. and P. Jehiel (2002b): "Information Acquisition in Auctions: sealedbid or Dynamic?" mimeo PSE and UCL.

Cramton, P., R. Gibbons, and P. Klemperer (1987): "Dissolving a Partnership Efficiently," Econometrica 55, 615-632.

Cremer, J and R. McLean (1985): "Optimal Selling Strategies under Uncertainty for a Discriminating Monopolist when Demands are Interdependent," Econometrica 53, 345-362

Cremer, J. and R. McLean (1988): "Full Extraction of the Surplus in Bayesian and Dominant Strategy Auctions," Econometrica 56, 1247-1257.

Dana, J. and K. Spier (1994): "Designing a Private Industry: Government Auctions with Endogenous Market Structure," Journal of Public Economics 53, 127-147.

Dasgupta, P., P. Hammond and E. Maskin (1979): "The Implementation of Social Choice Rules: Some General Results on Incentive Compatibility" Review of Economic Studies 46, 185-216.

Dasgupta, P., and E. Maskin (2000): "Efficient Auctions", Quarterly Journal of Economics 115, 341-388.

Das Varma, G. (2002): "Standard Auctions with Identity Dependent Externalities," Rand Journal of Economics 33, 689-708.

Das Varma, G. (2002): "Who Else is Bidding ? The Pareto Optimality of Disclosing Bidder Identities", Review of Economic Design 7, 155-171.

Das Varma, G. (2003): "Bidding for a Process of Innovation under Alternative Modes of Competition," International Journal of Industrial Organization 21, 15-37.

Fieseler, K., T. Kittsteiner, and B. Moldovanu (2003): "Partnerships, Lemons and Efficient Trade", Journal of Economic Theory 113, 223-234

Figueroa, N. and V. Skreta (2004): "Optimal Auction Design for Multiple Objects with Externalities," mimeo University of Minnesota. 
Gilbert, R. and D. Newbery (1982): "Preemptive Patenting and the Persistence of Monopoly," American Economic Review 72, 514-526.

Goeree, J. (2003): "Bidding for the future: signaling in auctions with an aftermarket," Journal of Economic Theory 108, 345-364

Gomes, A and P. Jehiel (2005): "Dynamic Processes of Social and Economic Interactions: On the Persistence of Inefficiencies," Journal of Political Economy 113, 626-667.

Graham, D. and R. Marshall (1987): "Collusive Bidder Behvaior at Single-Object Second-Price and English Auctions," Journal of Political Economy 95, 1217-1239.

Green J., Laffont J.J. (1979): "Incentives in Public Decision Making", North Holland.

Gresik, T.A. (1991): "Ex-Ante Incetive Efficient Trading Mechanisms without the Private Valuations Restriction", Journal of Economic Theory 55, 41-63.

Gruener, H.P., and A. Kiel (2004): "Collective Decisions with Interdependent Valuations", European Economic Review 48, 1147-1168.

Gui, H.,Mueller, R., and R. Vohra (2004): "Dominant Strategy Mechanisms with Multidimensional Types", discussion paper, Northwestern University.

Groves T. (1973): "Incentives in Teams", Econometrica 41, 617-631.

Hain, R. and Mitra, M. (2004): "Simple Sequencing Problems with Interdependent Costs", Games and Economic Behavior 48, 271-291.

Hansen R. (1985): "Auctions with Contingent Payments", American Economic Review 75, 862-865.

Heifetz, A. and Z. Neeman (2004): "On the Generic (Im)possibility of Full Surplus Extraction in Mechanism Design," mimeo, Boston University.

Hiriart-Urruty, J.P. and Lemarechal C. (2001): Fundamentals of Convex Analysis, Heidelberg: Springer-Verlag .

Holmstrom B. (1979): "Groves Schemes on Restricted Domains", Econometrica 
47, 1137-1144.

Holmstrom B., and R. Myerson (1983): "Efficient and Durable Decisions Rules with Incomplete Information", Econometrica 51, 1799-1819.

Hoppe, H., P. Jehiel and B. Moldovanu (2005): "License Auctions and Market Structure," forthcoming Journal of Economics and Management Science

Inderst, R. and C. Wey (2004): "The Incentives for Takeovers in Oligopoly", International Journal of Industrial Organization 22: 1067-1089.

Jackson, M. (2003): "Efficiency and Information Aggregation in Auctions with Costly Information," Review of Economic Design 8: 121-141.

Janssen, M. (2004): Auctioning Public Assets, Cambridge: Cambridge University Press.

Janssen, M., and B. Moldovanu (2004): "Allocation Mechanisms and PostAllocation Interaction" in Auctioning Public Assets, M.Janssen (ed.), Cambridge: Cambridge University Press.

Jehiel, P., Meyer-ter-Vehn, M., Moldovanu, B. (2004b): "Potential and Implementation", discussion paper, University of Bonn.

Jehiel, P., Meyer-ter-Vehn, M., Moldovanu, B., and W. Zame (2005) "The Limits of Ex-post implementation", discussion paper, University of Bonn.

Jehiel, P. and B. Moldovanu (1996): "Strategic Non-participation," Rand Journal of Economics 27, 84-98.

Jehiel, P. and B. Moldovanu (1999): "Resale Markets and the Assignment of Property Rights," Review of Economic Studies 66, 971-991.

Jehiel, P. and B. Moldovanu (2000): "Auctions with Downstream Interaction among Buyers," Rand Journal of Economics 31, 768-791

Jehiel, P., and B. Moldovanu (2001) "Efficient Design with Interdependent Valuations", Econometrica 69, 1237-1259.

Jehiel, P. and B. Moldovanu (2003): "An Economic Perspective on Auctions," 
Economic Policy 36, 271-308

Jehiel, P. and B. Moldovanu (2004): "The Design of an Efficient Private Industry," Journal of the European Economic Association 2(2-3), 516-525.

Jehiel, P., Moldovanu, B. and E. Stacchetti (1996): "How (not) to Sell Nuclear Weapons," American Economic Review 86, 814-829.

Jehiel, P., Moldovanu, B. and E. Stacchetti (1999): "Multidimensional Mechanism Design for Auctions with Externalities", Journal of Economic Theory 85, 814-829.

Jehiel, P. and A. Pauzner (2005): "Partnership Dissolution with Interdependent Values", forthcoming, Rand Journal of Economics

Johnson, S., J. W. Pratt and R. Zeckhauser (1990): "Efficiency Despite Mutually Payoff-Relevant Private Information: The Finite Case," Econometrica 58, 873-900.

Johnson, S., N. Miller, J. W. Pratt and R. Zeckhauser (2003): "Efficiency Design with Multidimensional, Continuous Types, and Interdependent Valuations," mimeo Kennedy School, Harvard University.

Jullien, B. (2000): "Participation Constraints in Adverse Selection Models", Journal of Economic Theory 93, 1-47.

Kamien, M., Oren S. and Y. Tauman (1992): "Optimal Licensing of CostReducing Innovations," Journal of Mathematical Economics 21, 483-509.

Kamien, M. and Y. Tauman (1986): "Fees versus Royalties and the Private Value of a Patent," Quarterly Journal of Economics 101, 471-492.

Katz, M. and C. Shapiro (1986): "How to License Intangible Property," Quarterly Journal of Economics 101, 567-590

Kirchkamp, O. and B. Moldovanu (2004): "An Experimental Study of Auctions with Interdependent Valuations", Games and Economic Behavior 48, 54-85.

Kittsteiner, T. (2003): "Partnerships and the Double Auction with Interdependent Valuations", Games and Economic Behavior 44, 54-76 
Kittsteiner, T. and B. Moldovanu (2005): "Priority Auctions and Queue Disciplines that Depend on Processing Time", Management Science 51, 236-248.

Klemperer, P. (2001), "How (Not) to Run Auctions: The European 3G Telecom Auctions," European Economic Review 46, 829-845.

Klemperer, P. (1999): "Auction Theory: A Guide to the Literature", Journal of Economic Surveys 13, 227-286.

Krishna, K. (1993): "Auctions with Endogenous Valuations: The Persistence of Monopoly Revisited," American Economic Review 83, 147-160

Krishna, V. (2003): "Asymmetric English Auctions," Journal of Economic Theory 112, 261-288.

Krishna, V., and E. Maenner (2001) : "Convex Potentials with an Application to Mechanism Design", Econometrica 69, 1113-1119.

Laffont, J.J. and E. Maskin (1982): "The Theory of Incentives: an Overview" in Advances in Economic Theory, ed. Hildenbrand W., Cambridge University Press 31-94.

Laffont, J. J and D. Martimort (1997): "Collusion under Asymmetric Information," Econometrica 65, 875-912.

Lavi, R., Mu 'alem A. and N. Nisan, (2004): "Towards a characterization of truthful combinatorial auctions", discussion paper, Hebrew University, Jerusalem

Ledyard, J. (1978): "Incentive Compatibility and Incomplete Information," Journal of Economic Theory 18, 171-189.

Maeda, A. (2003): "The Emergence of Market Power in Emission Rights Markets: The Role of Initial Permit Distribution", Journal of Regulatory Economics 24, 293-314.

Maskin, E. (1992): "Auctions and Privatization," in Privatization: Symposium in Honor of Herbert Giersch, edited by H. Siebert, 115-136. Tuebingen/ J. C.B. Mohr. 
Maskin, E. (2001): "Auctions and Efficiency", in Advances in Economics and Econometrics, Vol.1, M.Dewatripont et.al. (eds.), Econometric Society Monographs, Cambridge University Press.

McAfee, P. (1998): "Four Issues in Market Design", Revista Analisis Economico 13, $7-24$

McGuire, T. and M. Riordan (1995): "Incomplete Information and Optimal Market Structure: Public Purchases from Private Providers," Journal of Public Economics 56, 125-141.

McLean, R. and A. Postlewaite (2004): "Informational Size and Efficient Auctions", Review of Economic Studies 71, 809-827.

Mezzetti, C. (2004): "Mechanism Design with Interdependent Valuations: Efficiency," Econometrica 72, 1617-1626.

Milgrom, P. (2004): Putting Auction theory to Work, Cambridge: Cambridge University Press

Milgrom, P. and I. Segal (2002): "Envelope Theorems for Arbitrary Choice Sets," Econometrica 70, 583-601.

Milgrom, P. and R. Weber (1982): "A Theory of Auctions and Competitive Bidding," Econometrica 50, 1089-1122.

Moldovanu, B. and A. Sela (2003): "Licensing Bertrand Competitors," International Journal of Industrial Organization 21, 1 -13.

Molnar, J. and G. Virag (2004): "Revenue Maximizing Auctions with Externalities and Signaling", Working Paper University of Rochester.

Monderer D., and L. Shapley (1996): "Potential Games", Games and Economic Behavior 14, 124-143.

Muller, R., and R. Vohra (2003): "On Dominant Strategy Mechanisms", discussion paper, Northwestern University.

Myerson R., and M. Satterthwaite (1983): "Efficient Mechanisms for Bilateral 
Trading", Journal of Economic Theory 28, 265-281.

Neeman, Z. (2004): "The Relevance of Private Information in Mechanism Design," Journal of Economic Theory 117 , 55-77.

Ornelas, E., and J. Turner (2004): "Efficient Dissolution of Partnership and the Structure of Control", mimeo, University of Georgia.

Perez-Castrillo, D. and D. Wettstein (2002): "Choosing Wisely: A Multibidding Approach", American Econmic Review 92, 1577-1587.

Perry, M. and P. Reny (2002): "An Efficient Auction ", Econometrica 70, 11991213.

Pesendorfer, W, and J. Swinkels (1998): "Efficiency and Information Aggregation in Auctions", American Economic Review 90, 381-411.

Riley, J. and W. Samuelson (1981): "Optimal Auctions", American Economic Review 71: 381-392.

Roberts, K. (1979): "The Characterization of Implementable Choice Rules" in Aggregation and Revelation of Preferences, ed. Laffont J.J., North Holland.: 895-?

Rochet, J. C. (1985): "The Taxation Principle and Multitime Hamilton Jacobi Equations," Journal of Mathematical Economics 14, 113-128.

Rodriguez, E.G. (2002): "Auctions of Licences and Market Structure", Economic Theory 19, 283-309.

Vickrey, W. (1961): " Counterspeculation, Auctions and Competetive Sealed Tenders," Journal of Finance 16, 8-37.

Wilson, R. (1979): "Auctions of Shares," Quarterly Journal of Economics 93, 675-689.

Wilson, R. (1969): "Competitive Bidding with Asymmetric Information" Management Science 13: 816-820.

Waehrer, K. (2003): "Hazardous Facility Siting when Cost Information is Private", Journal of Public Economic Theory 5, 605-622. 